\begin{tabular}{|l|l|l|l|l|l|}
\hline MUNIBE Antropologia-Arkeologia & $n^{\circ} 69$ & $343-365$ & DONOSTIA & 2018 & ISSN 1132-2217 • eISSN 2172-4555 \\
\hline
\end{tabular}

\title{
La figura del cazador en las Bardenas Reales de Navarra. Estudio etnográfico de la caza en un paisaje comunal semidesértico
}

\author{
The figure of the hunter in the Royal Bardenas of Navarre. \\ Ethnographic study of hunting in a semi-desert communal landscape
}

PALABRAS CLAVES: Caza, cazador, Bardenas Reales, paisaje cultural, Navarra, Etnografía cinegética. GAKO-HITZAK: Ehiza, ehiztaria, Errege Bardeak, kultur paisaia, Nafarroa, etnografia zinegetikoa. KEY WORDS: Hunting, hunter, Royal Bardenas, cultural landscape, Navarre, Hunting Ethnography.

\section{Ma Rosario MATEO PÉREZ(1) y Pablo ORDUNA PORTÚS( ${ }^{(2)}$}

\section{RESUMEN}

La caza ha sido una práctica tradicional complementaria de otras actividades económicas en muchas sociedades rurales como las que han congozado en el territorio de las Bardenas Reales. Desde mitades del siglo XX se ha asistido a un repunte de su presencia en este paisaje navarro en el contexto de una moderna interpretación deportiva. Sin embargo, en esta inmensa comarca semidesértica aún se conservan algunos testimonios de aquellos cazadores que fundamentaban su labor cinegética en técnicas tradicionales. Atendiendo al examen del trabajo de campo, las fuentes orales y la documentación de archivo, este artículo recoge la información relativa a una vieja figura -la del cazador- que estuvo enmarcada en un contexto autárquico ya desaparecido en este territorio. El análisis de los datos intenta reconstruir el sistema de cacería seguido por la población local y su situación en el conjunto del patrimonio etnográfico y cultural de dicha comarca.

\section{LABURPENA}

Ehiza gizarte landatar askotan beste jarduera ekonomiko batzuen ekintza tradizional osagarria izan da. Hori izan da, adibidez, Errege Bardeak eremuko gizarte landatarren kasua. XX. mendearen erdialdetik, kirol-interpretazio modernoaren harira, Nafarroan handitu egin da horren presentzia. Dena den, eskualde erdibasamortutar erraldoi horretan, oraindik ere, beren jarduera zinegetikoaren oinarritzat teknika tradizionalak zituzten ehiztari haien testigantza batzuk topa ditzakegu. Landa-lanaren azterketa, ahozko iturriak eta artxibategiko dokumentazioa oinarritzat hartuta, artikulu honek jasotzen du dagoeneko lurralde horretan desagertuta dagoen testuinguru autarkikoan jasota egon zen garai bateko figura bati buruzko informazioa. Datuen azterketaren bidez, bertako biztanleek erabiltzen zuten ehizako sistema eta eskualde horretako ondare etnografiko eta kulturalean betetzen duen tokia berreraikitzen saiatuko gara.

\begin{abstract}
Hunting has been a traditional trade in many rural societies that have inhabited the Royal Bardenas. From the middle of the 20th century, there has been a rebound of hunting in the Navarrese landscape through modern amateur interpretation. However, in this immense semi-desert territory there are still some stories of hunters who hunt using traditional techniques. Using fieldwork, oral sources and historical files, this paper collects information about this ancient figure - "the hunter" - that has been framed in an autonomous context and yet has disappeared from this territory. Data analysis attempts to reconstruct possible old hunting systems followed by local hunters, placing them within the ethnographic and cultural heritage of this region.

Throughout the past decades there has been a substantial change in the figure of the hunter in the Bardena. Thus, in these years, the hunting has experienced a rebound in this huge communal territory of southern Navarre. However, the presence of the job of 'traditional hunter' has disappeared in the region. It's true that before those who lived on the pieces collected constituted a minority group in the area. But, it's also true that it had its small moments of boom in periods of economic shortages - bad harvests or famines- or the need to end with certain animal pests. Thus, in the post-Spanish Civil War era, hunger gripped many humble people in that semi-desert environment. These persons chose to have their small supply of food and money with the hunt. Also, some of them didn't hesitate to use illegal techniques and hunt furtively.

Even so, in the Bardena, the social value of the practice of hunting in a bunch is old and remains visible. Such the trace of them has also been indicated in the landscape through different place names. At the same time, the memory of different capture methods is maintained. Although, it's important to mention that some of the hunting techniques were abandoned or prohibited. In addition, part of a traditional knowledge linked to an old skill and a way of interacting with the balanced medium was losing. In short, then the hunter had already become a new recreational figure away from the traditional model.
\end{abstract}

\footnotetext{
(1) Olcairum Estudios Arqueológicos, S. L. olcairum@gmail.com

(2) Investigador del Grupo Etniker - Navarra. Profesor Adjunto en la Universidad Internacional de La Rioja y del Basque Culinary Center eurienea@ hotmail.com
} 


\section{INTRODUCCIÓN}

En los cabezos y barrancos del desierto de las Bardenas Reales de Navarra aún se encuentran algunos cazadores que recuerdan el pasado y el conocimiento tradicional de esta antigua actividad. Se trata de gente que supo sacar provecho a los recursos de aquella comarca en apariencia baldía y despoblada. En la actualidad el aprovechamiento cinegético se ha convertido en un motor socioeconómico de muchas regiones rurales de Europa (Farfán et al., 2004: 42). Si bien es practicada por un porcentaje reducido de la población, siempre ha tenido un gran peso cultural y etnológico para muchas comunidades. Se puede afirmar que ha sido un componente indisociable de la capacidad de supervivencia de los pobladores de la Bardena. Entre el grupo de cazadores bardeneros siempre ha transitado un carácter identitario particular que ha dado cierta homogeneidad a un colectivo ya de por sí muy heterogéneo en los perfiles de quienes lo componían. En tiempos recientes estos rasgos quizás se han agrupado en torno a la figura del nuevo cazador deportivo. Es un personaje alejado de aquel trampero, alimañero o furtivo que no veía en el cobro de piezas un entretenimiento sino un modus vivendi complementario para su subsistencia.

Sánchez (2013: 11-12), señala que el ambiente sociocultural determina la actitud e imagen del cazador, pero desde el punto de vista etnográfico ambos conceptos adquieren "un plano diferente". Por un lado existe el modelo ideal en el arte de la caza y por otro la realidad que determina el medio y la cultura donde se ubica. Esta 'práctica en el campo' no sólo sociabilizaba a los cazadores sino a un sinfín de personajes que basculaban entre la ganadería, agricultura y otros oficios menores (Florido y Palenzuela, 2017: 59). Esto en las Bardenas se hace más que palpable dando lugar a determinados caracteres etnográficos conformadores del patrimonio polisémico de la caza en este enorme comunal navarro.

\section{2. ÁREA DE ESTUDIO}

En el sur de Navarra se extienden 42.000 ha. que componen el territorio denominado Bardenas Reales. Se trata de un espacio semidesértico donde el clima mediterráneo se transforma adquiriendo rasgos extremos de sequedad y frío. Estas condiciones, unidas a la orografía y composición del suelo de la comarca, han sido factores condicionantes tanto de su diversidad biológica como de su papel antropológico (Compaired et al., 2003: 19). El suelo de yeso, limos, arcillas y areniscas presenta una fuerte erosión que propicia tierras aparentemente baldías - badlands- donde los cabezos -cerros testigo- y las planas -mesetas- evidencian el desgaste por las correderas de agua ocasionales y el viento. El modelado se desarrolla sobre la alternancia de materiales blandos y duros, que no retiene el agua proveniente de irregulares precipitaciones torrenciales más que en pequeñas balsas, dejando una superficie tabular (Desir y Marin, 2009: 195-213 y 2010: 63-72; Lozano-Valencia, 2017: 201-225). En estos espacios, la

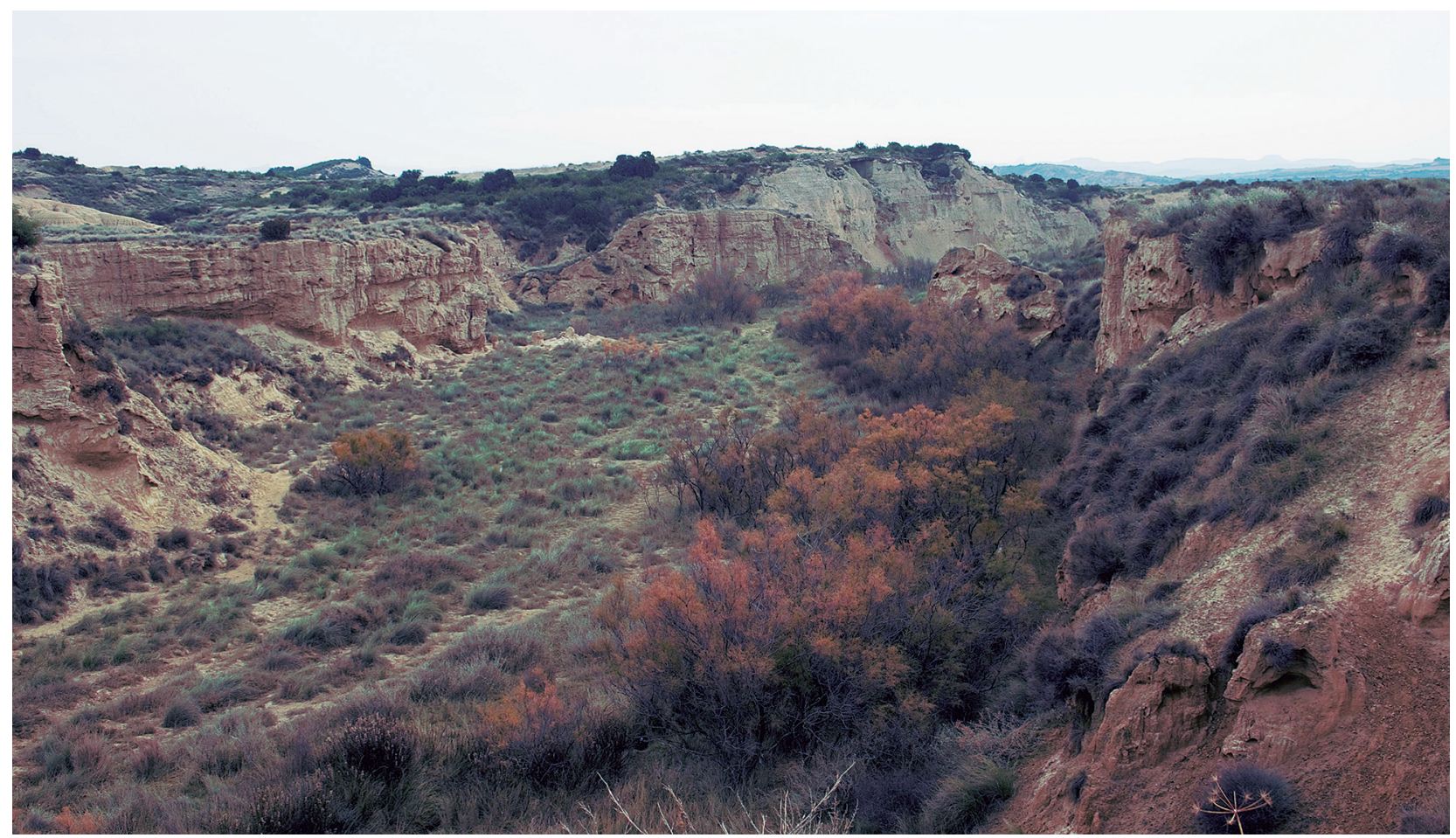

Fig. 1. Paisaje semidesértico y estepario de la Bardena. Ma Victoria Portús. / Semi-desert and steppe landscape of the Bardena. Mª Victoria Portús. 
biodiversidad -aunque aparenta mostrarse pobre- sigue manifestándose con un carácter estepario más típico del levante peninsular. A ella se le suman los aportes de cultivos y cabezas de ganado trashumante que invernan en la comarca. Se exhibe así una rica realidad natural y antropológica nunca deshabitada del todo y con una huella antrópica constante desde antiguo.

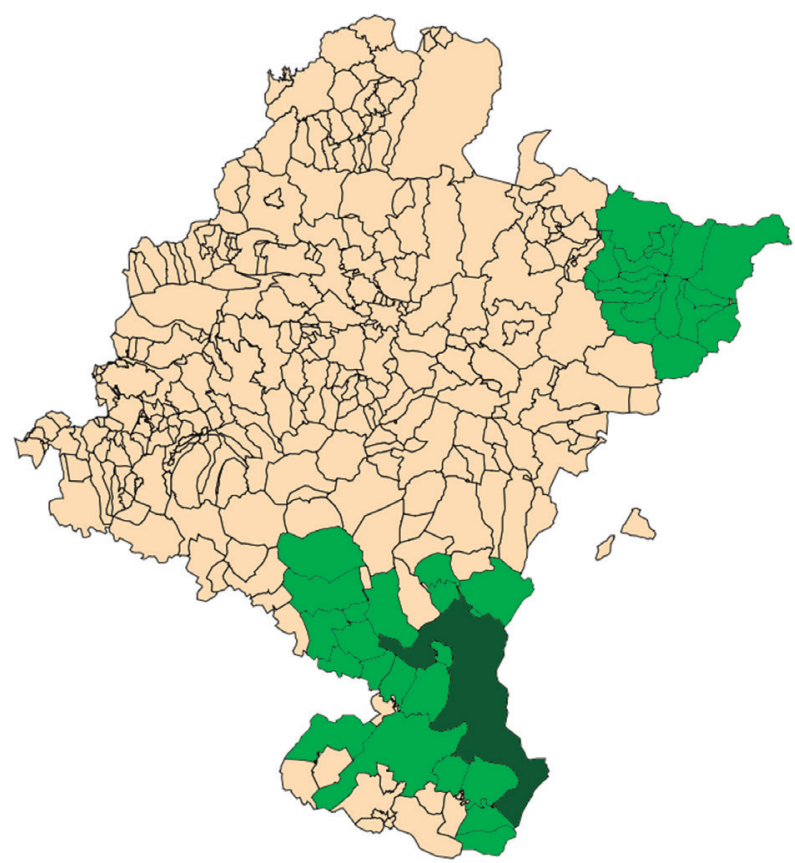

Fig. 2. Localización de las Bardenas y sus entes congozantes. Elaboración propia. / Location of the Bardenas and its congozante entities. Own elaboration.

A pesar de tratarse de un espacio hoy sin núcleos de población estables, en él se han hallado yacimientos arqueológicos que nos indican la presencia humana desde la Edad de Bronce (Sesma y García, 1994: 89218; Beguiristáin et al., 2010: 1999-225). Desde este periodo incluso existen referencias arqueológicas que manifiestan la aportación de piezas de caza cobradas por los pobladores. Según Sesma y García (1994: 142), "Ia aportación de la fauna salvaje en forma de caza no fue muy significativa". Aunque el determinar su importancia puede ser dificultoso sí se pueden mencionar como las especies más consumidas entonces, además del conejo, al ciervo y el jabalí. También señalan los autores que "se capturan otros animales, como algunos félidos (lince y gato montés), tejón, corneja", lo que nos indica un tipo de clima diferente al actual y la probable presencia de un bosque caducifolio termófilo con cauces de agua.

Ahora bien, tras el Medievo jamás volvieron a desarrollarse núcleos permanentes en este paisaje bardenero (Iriarte, 1993 y 2001). Los asentamientos humanos no prehistóricos han sido pastoriles y teniendo un carácter estacional seminómada. Se trata de pastores trashumantes o transimetantes llegados desde los diferentes pueblos o valles congozantes (Orduna, 2013). Como ta-

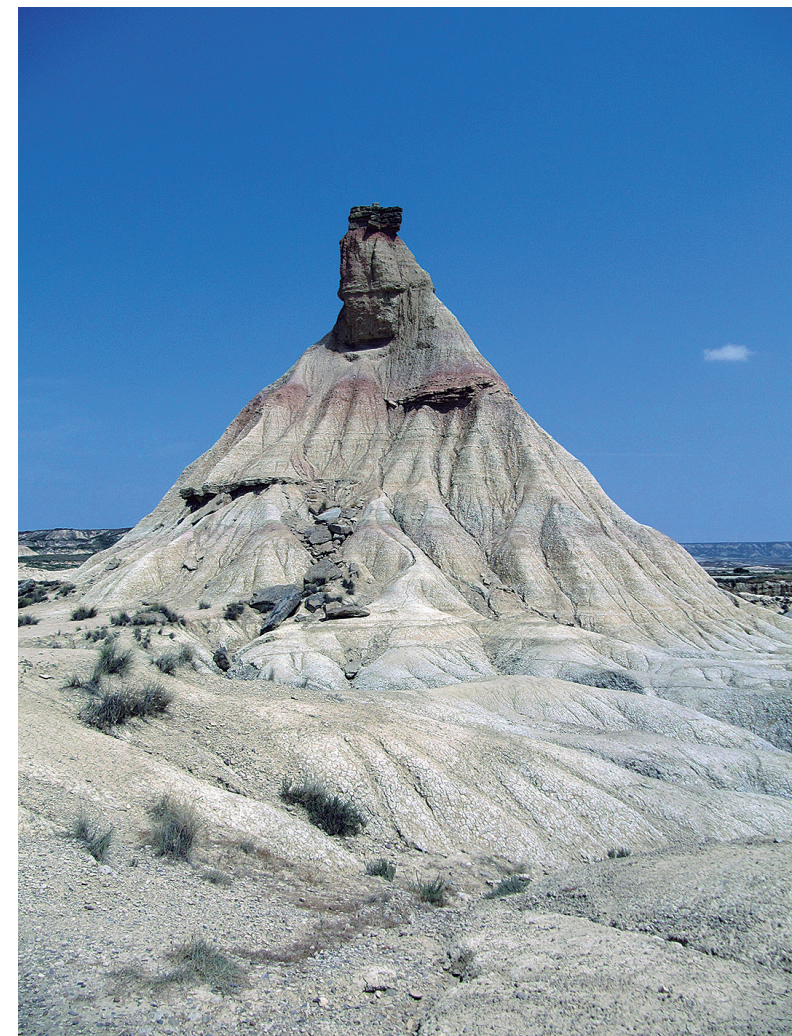

Fig. 3. Cabezo de Castildetierra. M ${ }^{a}$ Victoria Portús. / Castildetierra Promontory. M ${ }^{a}$ Victoria Portús.

les entes la terminología local se refiere a aquellos municipios que pueden disfrutar de este enorme comunal. En la Ribera de Navarra lo son Tudela, Arguedas, Valtierra, Cadreita, Caparroso, Buñuel, Cabanillas, Mélida, Villafranca, Corella, Milagro, Fustiñana, Santacara, Cortes, Marcilla, Peralta, Funes, Falces y Carcastillo. Junto a ellos, son también congozantes el Monasterio de la Oliva -ubicado en el término de Carcastillo- y los dos valles pirenaicos de Roncal y Salazar. Todos ellos han acudido a la Bardena para explotar los recursos del territorio, destacando los pastores, agricultores, carboneros, yeseros, pegueros -fabricantes de pez-, mieleros apicultores- y, por supuesto cazadores (Orduna, 2014).

El ecosistema de la Bardena alberga una fauna en cuyo centro se puede colocar al grupo de aves. En este conjunto, entre migratorias y no, podemos distinguir más de un centenar de especies con las rapaces y esteparias a la cabeza (Compaired et al., 2003). Algunas de ellas, como la charra o malviz -Turdus sp.- o la perdiz roja -Alectoris rufa- son susceptibles piezas de caza. Hay presencia también de cierta fauna vertebrada objeto de captura para el consumo, por encargo de sus pieles o simplemente su muerte al ser alimañas dañinas para ganaderos y agricultores. Entre este grupo de mamíferos destacan el conejo -Oryctolagus cuniculus-, jabalí -Sus scrofa-, corzo -Capreolus capreolus-, zorro - Vulpes vulpes- o liebre ibérica -Lepus granatensis-, aún presentes; y el lobo -Canis lupus signatus- ya desaparecido. 


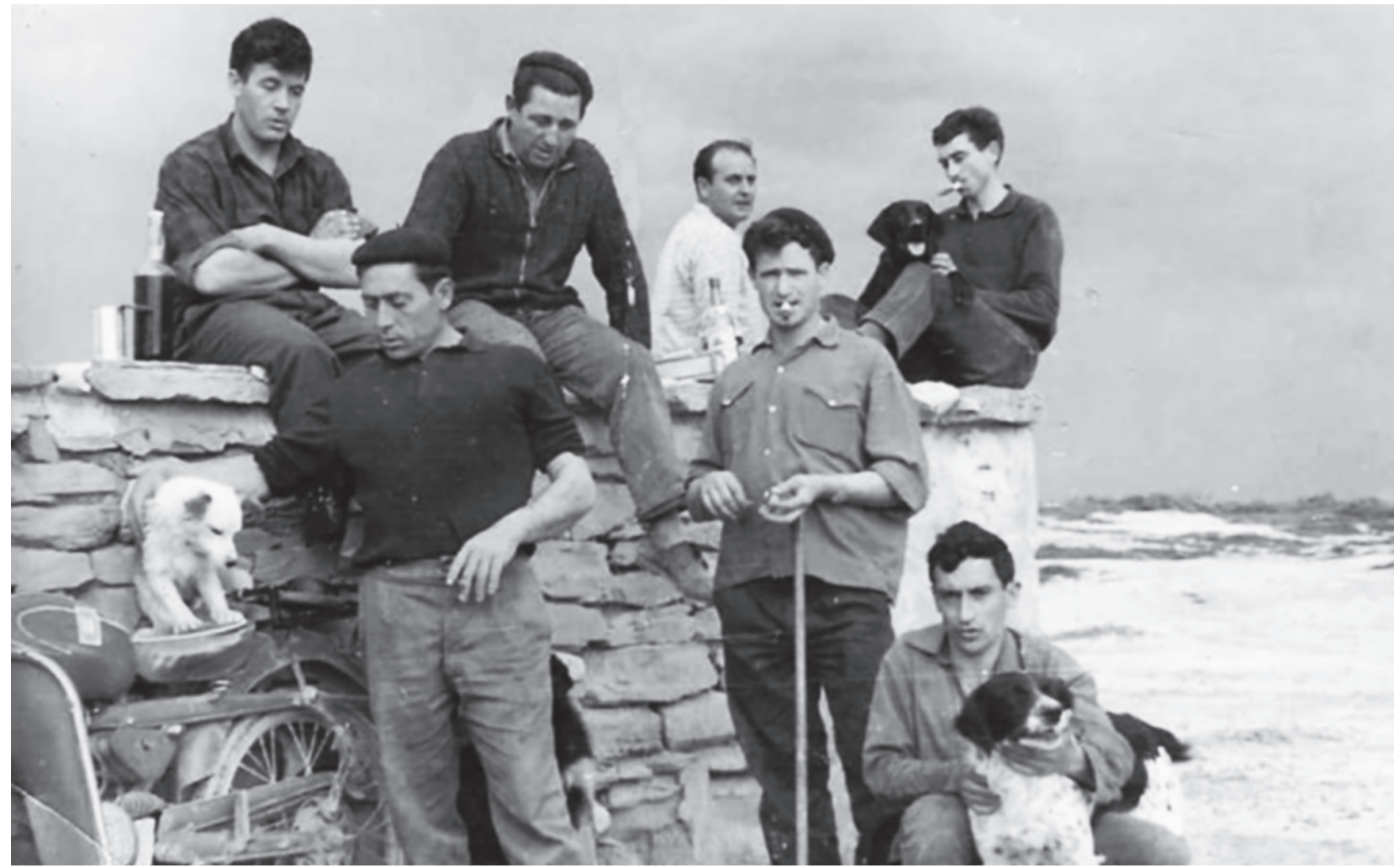

Fig. 4. Cuadrilla de cazadores en Bardenas a la hora del almuerzo. Ayuntamiento de Arguedas / Hunters' group in Bardenas at lunchtime. Council of Arguedas.

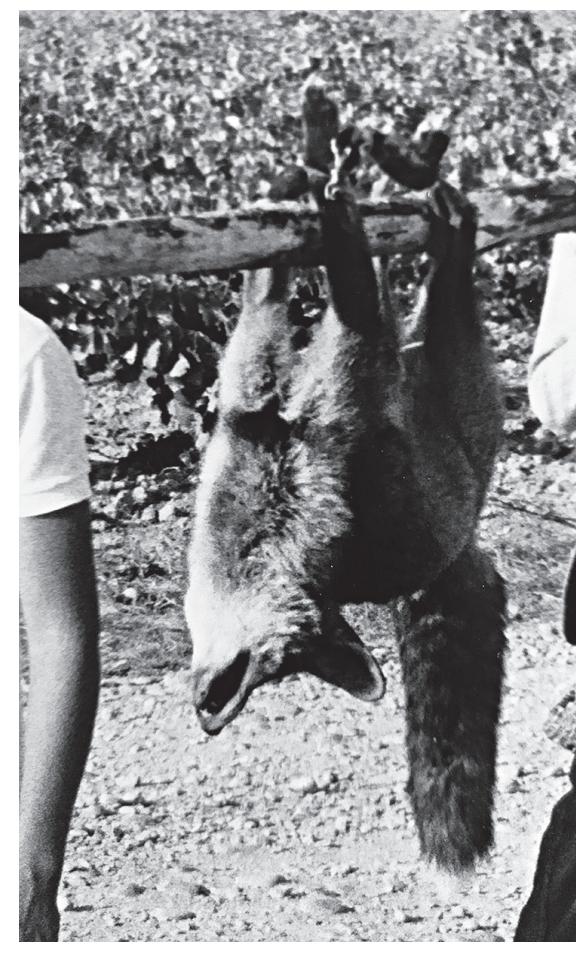

Fig. 5. Zorro transportado para ser valorado. Fondo Fotográfico Familia Guibert-Valencia / Fox transported to be valued. Guibert-Valencia Family Photography Collection.

\section{RESULTADOS}

En el devenir histórico del disfrute en este paraje, una de las condiciones más importantes que se puso para poder ejercer el derecho a la caza fue el ser vecino de una de las entidades congozantes o, en su defecto, tener el permiso concedido de la Junta del comunal o los monarcas del Reino. En 1527, Carlos I confirmaba el privilegio otorgado en 1472 por doña Leonor, princesa de Viana, en favor de Caparroso para que pudieran aprovechar usos como el disfrute de la caza ${ }^{1}$. Sin embargo, este tipo de derechos y concesiones no siempre estaban tan claros entre los entes congozantes. De esta manera, entre los siglos XVI y XVII, se suceden los pleitos relativos al disfrute del aprovechamiento cinegético. En 1537, era la villa de Valtierra quien demandaba al fiscal y patrimonial del Reino y a ciertos vecinos de Caparroso y Arguedas defendiendo su derecho a ejercer la caza en los parajes bardeneros de la Carbonera y Mediacabañas donde los demandados les habían decomisado injustamente "aparejos de caza"2. Por su parte, la ciudad ribereña de Tudela mantuvo diferentes pleitos con el fiscal del Reino exigiendo el reconocimiento de ese derecho a cazar en la Bardena y otros arriendos para extraer o elaborar productos en su interior ${ }^{3}$.

${ }^{3}$ ARGN, TT. RR., 16020471, 097940, 072228 y 015212. 
La caza ha estado regulada desde antiguo en $\mathrm{Na}$ varra, como ha quedado recogido en obras tan diversas como sus Fueros o el texto titulado Los paramientos de la caza de 1180, que es atribuida al monarca navarro Sancho el Sabio (Fradejas, 1988). Hoy en día, en la Comunidad Foral de Navarra, el ordenamiento que regula el aprovechamiento cinegético está contenido en la Ley Foral 17/2005 de Caza y Pesca de Navarra y por la Orden Foral de Vedas, que se renueva anualmente (Santamaría, 2003-2016). Esta legislación incide en la protección de especies cuya captura está prohibida o limitada, en las modalidades de caza y sus condiciones permitidas, y sobre todo en la salvaguarda del carácter social que el aprovechamiento cinegético tiene en la Comunidad Foral (Guibert, 2005: 22-25). La base de cualquier aprovechamiento de caza en Navarra es la constitución del acotado que está promovido por el titular privado de los terrenos o la entidad pública o local. En segundo lugar, se debe aprobar un Plan de Ordenación Cinegética -POCde carácter técnico y con vigencia máxima de cinco años. En él se establecen y categorizan las especies objeto de caza, su densidad y objetivo demográfico. También determina los métodos de captura, las épocas de permiso y veda y el programa económico donde se reflejan el sistema de vigilancia, a propuesta de mejoras y prevención de daños si los hubiera.

En el caso de las Bardenas, tradicionalmente, la caza ha sido un congoce-disfrute- menor con respecto a la importancia o protagonismo que han tenido la ganadería o agricultura. El área que compone este territorio comunal han estado administrada históricamente en función de sus propias Ordenanzas. Estas actúan como la 'norma' reguladora de sus usos intentando equilibrar el peso de los disfrutes principales y el espacio de actuación reservado para aquellos menores frente a los principales agropecuarios (Lavilla, 2012). La Reseña histórica de los títulos.... (ed. 1977) apunta cómo la evolución histórica y antropológica consolidó entre sus moradores cierta variedad de derechos bien reglados. Este tipo de normativas ha intentado respetar determinadas particularidades en los usos pero, a su vez, lograr un aprovechamiento sostenible y sujeto al derecho foral navarro. Por otro lado, el cumplimiento de las mismas ha influido desde el punto de vista histórico y etnográfico en el desarrollo de actividades como la caza en el interior de sus límites.

A lo largo de la Historia, en los tribunales reales navarros se han sucedido diferentes procesos por causas derivadas de la contravención de la normativa impuesta para la caza en las Bardenas. Así, en 1562 el fiscal del Reino y su patrimonial demandaban a varios vecinos de Arguedas por no seguir correctamente las leyes de caza en el territorio ${ }^{4}$. En 1589 llevaban a los juzgados a varios oriundos de Carcastillo por cazar de forma indebida en las Bardenas ${ }^{5}$. En otros casos los propios cazadores eran a veces quienes esgrimían sus derechos en las salas de justicia. Así, en 1610, el vecino de Villafranca Antonio Martínez de Sarasa acusaba a varios cazadores de Caparroso por los réditos de un censo de 500 ducados afirmando que además habían ejercido fuerza en su aprovechamiento de varios disfrutes y de la caza en la Bardena ${ }^{6}$.

Hoy en día, en las Ordenanzas se concretan y plasman los aprovechamientos cinegéticos dentro de la regulación desarrollada en el artículo 3 del capítulo III, donde se determina que el derecho a cazar se dará "en las épocas no vedadas por los Reglamentos Generales". Así mismo, como se detallará más adelante, en el Capítulo XI -artículo 81- se establece el oficio y limitaciones de los alimañeros ${ }^{7}$. Tal reglamentación quedó renovada en 1990 cuando se inició la elaboración del primer POC propio de las Bardenas. Desde ese año se han ido implementando nuevos planes quinquenales con modificaciones y variaciones. Los objetivos de los mismos han sido reglamentar el uso cinegético con la imposición de limitaciones hacia el cazador -incremento de áreas de reserva, disminución de días en los que se puede practicar la caza- para adecuar su actualización a la legislación foral vigente. Así, las especies consideradas de caza presentes en las Bardenas son la liebre, la perdiz, el conejo, el jabalí, el zorro, la paloma, la malviz y aves acuáticas. En el mismo, se consideran como posibles piezas de caza anecdóticas al avefría, la becada, los córvidos, las agachadizas, los estorninos y la codorniz.

En la actualidad, existe una Asociación de Cazadores y Pescadores -ASCAPEBAR- que, sin ánimo de lucro, agrupa a un buen número de socios con objeto de desarrollar su actividad de forma regulada. Para poder integrarse en la misma, entre otros requisitos, la Junta de Bardenas exige que la persona entregue un "certificado de vecindad en el que se haga constar la condición de vecino -de un pueblo congozante- con la antelación exigida por las ordenanzas de la comunidad: 10 años de vecindad continuada y 9 meses de residencia efectiva al año". En definitiva, el examen de la evolución de las Ordenanzas y la transformación de la figura del cazador permite obtener una clara diapositiva de la transformación antropológica, cultural y social que ha sufrido el rito de la caza en este espacio del sur de Navarra.

\footnotetext{
${ }^{4}$ ARGN, TT.RR., 010451.

5 ARGN, TT.RR., 056756.

6 ARGN, TT.RR., 200680. Ver: ARGN, TT.RR., 095318 y 295722

7 Incluso, en 1953 se crearon en el estado las Juntas de Extinción de Animales Dañinos para regular el oficio de alimañero.
} 


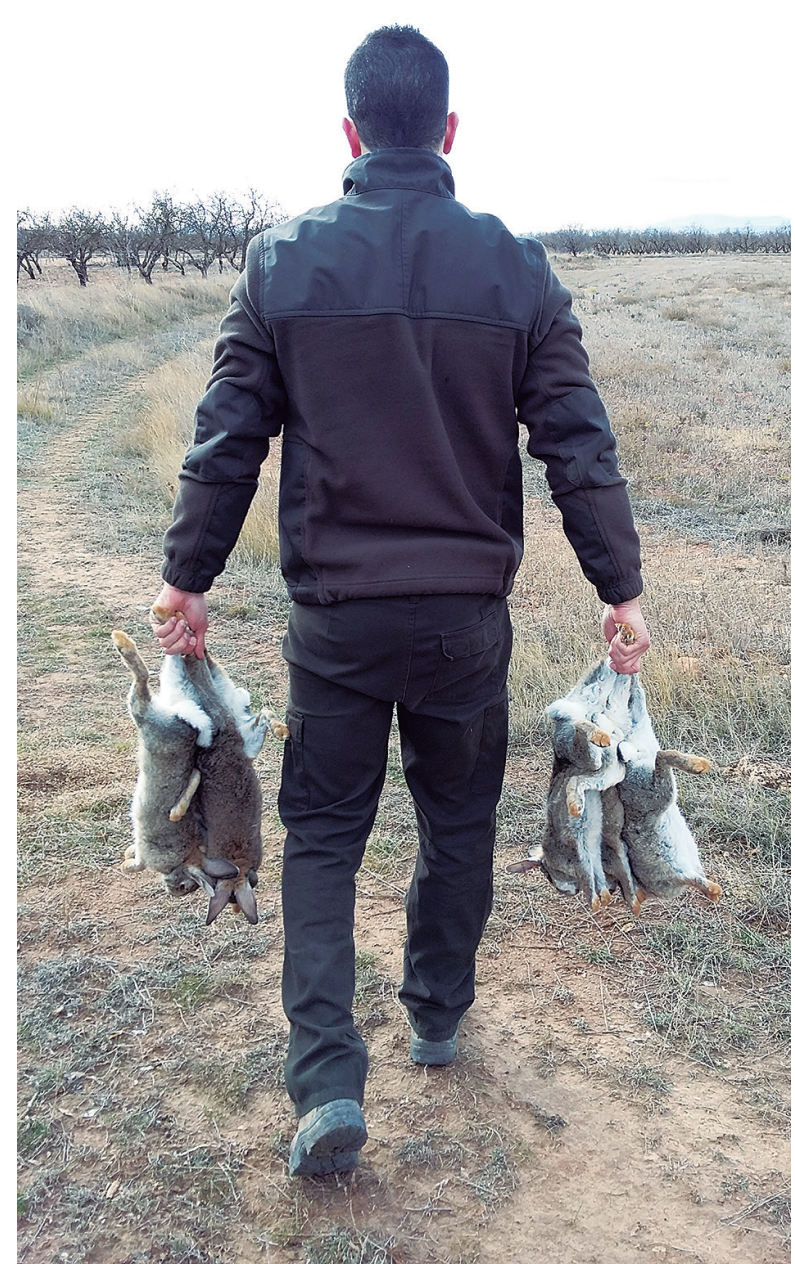

Fig. 6. Cazador en un pueblo congozante con sus piezas cobradas. Fondo Fotográfico Familia Guibert-Valencia./ Hunter in a congozante village with his pieces shot. Guibert-Valencia Family Photography Collection.

\section{LA FIGURA DEL CAZADOR}

\subsection{El cazador tradicional}

Quizás la figura del cazador 'legal' pueda parecer la más sencilla de definir de las tres. Es verdad que es así en lo referente a la sociedad tradicional que ha disfrutado de las Bardenas hasta finales del siglo XX. En ese contexto, al margen de los alimañeros o furtivos, sólo se conocía el papel cinegético de aquellos congozantes que ejercían la caza dentro de la normativa vigente bien como medio de sustento o entendida como oficio para ganarse un jornal suplementario -si no exclusivo- a sus quehaceres habituales. Ahora bien, desde los años 80 de la pasada centuria estas variantes de la figura del cazador se han ido relegando a la memoria dando lugar a la aparición de un nuevo 'cazador deportivo'. Sin embargo, a nivel etnográfico, hay que hacer hincapié en la figura del antiguo cazador bardenero vinculado a una sociedad muy asociada a la dependencia del territorio y sus recursos. Tal fue esta ligazón con el terruño que determinados topónimos menores de la comarca remiten al arte de la caza. Se localiza así la llamada Cabaña de los Cazadores, donde aún se reúnen estos previamente o al acabar sus partidas cinegéticas. Lugares como la Plana del Perdigón, la Loma del Perdigón o Peñapalomera evocan tanto a las crías de la perdiz roja -perdigones- como a los emplazamientos elegidos como puestos de caza. Incluso ya se referencia en 1537 una cabaña llamada Caseta del Perdiguero (Jimeno, 1993).

Se ha señalado que, a diferencia de otros territorios de la Península, en Navarra la caza tiene principalmente un carácter social. Esto es así tanto en la montaña del norte como en el Mediodía de la Ribera. Incluso en un espacio tan despoblado y duro para la supervivencia como el de la Bardena, tal caracterización de la actividad cinegética ha estado presente a lo largo del tiempo y ha cobrado más fuerza si cabe desde hace unas pocas décadas. En tal evento el protagonista era el cazador que, como se ha mencionado, podía estar personificado en un vecino de los pueblos colindantes o en algún pastor trashumante llegado en el invierno desde los valles congozantes del Pirineo. En el caso de estos últimos, quienes pastoreaban en este inmenso comunal no eran cazadores 'de oficio' sino por necesidad. Así, en estas tierras su presa más habitual eran los conejos o liebres que se capturaban mediante cepos, trampas o con el golpeo del palo cuando salían por las bocas de sus madrigueras unos o estaban dentro de la cama -guarida a cielo abierto- otras. Esta última técnica era una operación que necesitaba sigilo y conocer bien el terreno, actitudes ambas muy propias de unos hombres habituados a recorrer diariamente esos terrenos de eriales, conocedores de los escondijos de los animales y que sabían estar quietos y en silencio largo rato. Ahora bien, entre ellos por el contrario no ha sido frecuente la captura de perdices, malvices u otros pájaros ya que tal trabajo requería dedicación exclusiva y no podía realizarse de forma ocasional o pareja al oficio de pasturaje ${ }^{8}$. Sí es cierto que al igual que los alimañeros, como se verá, no dudaron en preparar trampas o cepos para atrapar a aquellos zorros que atacaban a los corderos recién paridos (Barandiarán y Manterola, 2000: 654). Por ello, se puede decir que el verdadero cazador tradicional de la Bardena era el originario de los pueblos navarros de la Ribera del Ebro. Como apunta el informante Miguel Guibert, en su familia de Carcastillo se tenía claro el ciclo: una semana alojados en la caseta de la Bardena mientras la siega de la mies y a ratos la caza para mantenerse.

\footnotetext{
${ }^{8}$ Por el contrario, en la freguesia de Aguas Belas, Portugal, los pastores conocían la práctica de la caza de la perdiz mediante un curioso modelo de caixinhas de pedra que al parecer tenían un origen tumular prehistórico. (Vilaça et al., 2004: 141).
} 

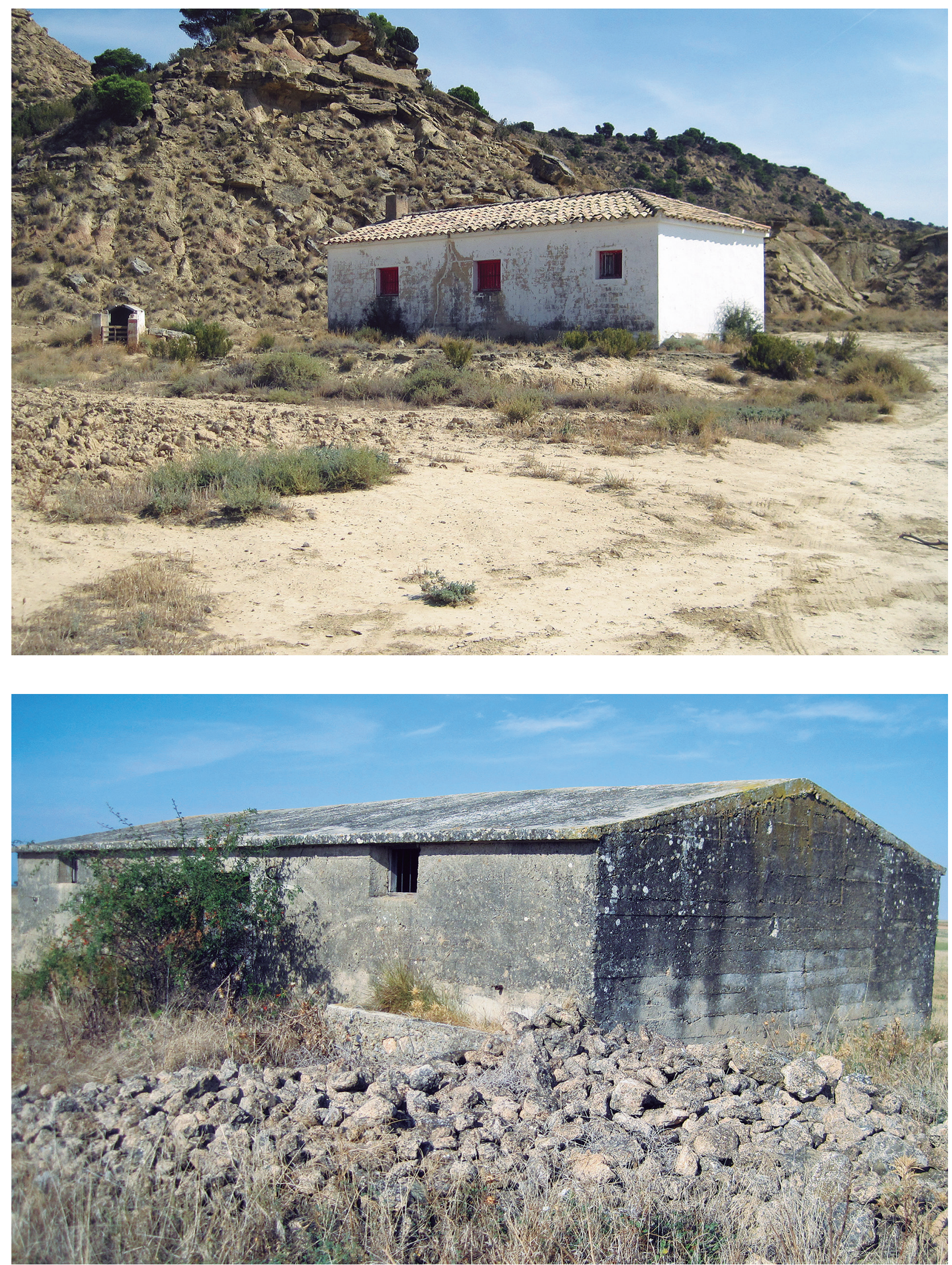

Figs. 7-8. Cabañas de los Cazadores y del Raboso. Txaro Mateo / Cazadores and El Raboso cabins. Txaro Mateo. 
Según el vecino nonagenario de Fustiñana Luis Agramonte, el 'verdadero cazador' siempre ha sido legal y ha renegado del furtivismo aunque conozca las técnicas empleadas por ellos y sepa que pudieran hacerle más fácil la captura de sus presas. Sin embargo, comprende que el hambre que se pasó pueda disculpar a algunos que utilizaban tales mañas en pro de lograr las presas que les sirvieran de alimento. Según el informante existen una serie de rasgos que por el contrario definen a aquel que hizo de la destreza cinegética una forma de vida dentro del respeto a la norma. Por un lado la habilidad que debía mostrar ya que, entonces y ahora, "no todo el mundo puede ser cazador". Agramonte matiza que para ser un buen trampero o tirador hay que ser listo, paciente, disciplinado, querer el campo y conocerlo. Además, hay que saber escuchar a los perros si se llevan y a los compañeros si se tienen. Este rasgo de cercanía al camarada o al can es un determinante antropológico clave de la figura del cazador, no sólo en las Bardenas sino en el conjunto de la sociedad navarra vinculada a la acción cinegéti- ca. Quizás por ello, otro rasgo que señala es el propio orgullo que tiene quien caza de su afición u oficio: "un cazador es cazador desde que se acuesta hasta que se vuelve a acostar". Según él, el manejo de estas artes de presa le ha permitido entender más a los animales y a los hombres. Derivado de todo ello siempre surge la satisfacción, y en cierto modo necesidad, por que el interés siga en el seno de la familia: "mis hijos, nietos e incluso bisnietos son cazadores". En este caso, como en muchos otros, se ha generado una transmisión en el hogar de todos los conocimientos tradicionales -entre los varones- y los valores -en todo el conjunto del grupo- asociados a la caza. Y al igual que en el hogar tal actividad debe generar amistad: "Ios mejores amigos son los de la caza". Y para él es un valor añadido el haber podido cazar hasta los 96 años con mucha lealtad al mismo grupo o cuadrilla de caza incluso, siendo joven, marchando con ellos "varios días y dormir en cabañas" portando la comida en el morral de cuero - badana- o tela gruesa y un rusero o zacuto para trasladar a casa las piezas cobradas.

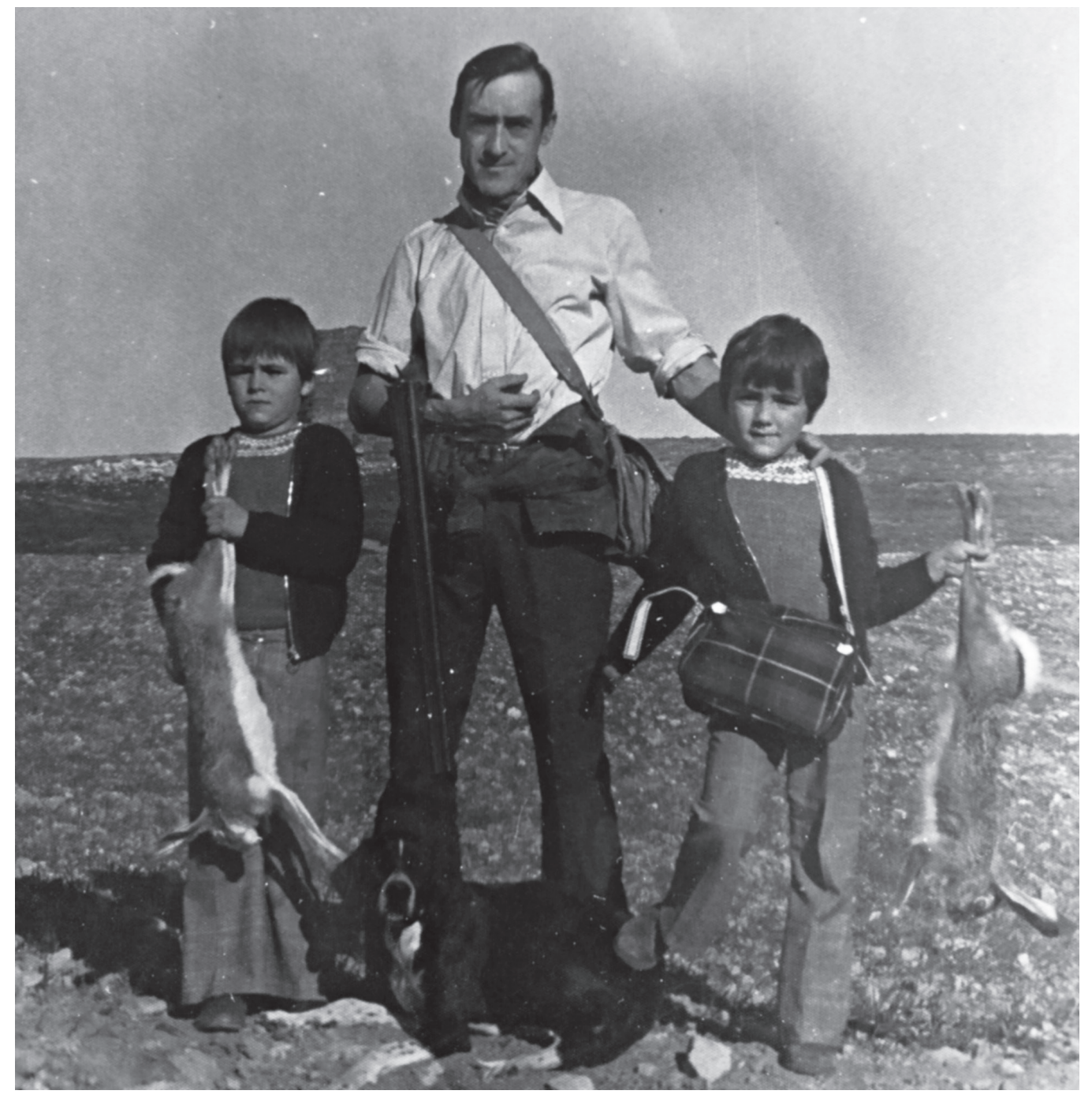

Figs. 9. Dos generaciones de cazadores en las Bardenas. Fondo Fotográfico Familia Guibert-Valencia. / Two generations of hunters in the Bardenas. Guibert-Valencia Family Photography Collection. 
Por su parte, otro de los encuestados refrendaba todas estas opiniones relatando que su padre le enseñó que "lo más importante en la caza es ir despacio, lento" pero seguro. Por ello siempre le decía que en tales faenas lo mejor es "perro viejo y cazador cojo". Como matiza Sánchez (2007: 3):

"La percepción, la mirada y su relevancia cognitiva, hace que la interpretación de un mismo paisaje sea diferente según la persona y el colectivo que lo active. Un mismo territorio, un mismo entorno, una misma naturaleza será pensada y percibida de forma distinta, y a partir de ahí la actuación sobre ella también diferirá".

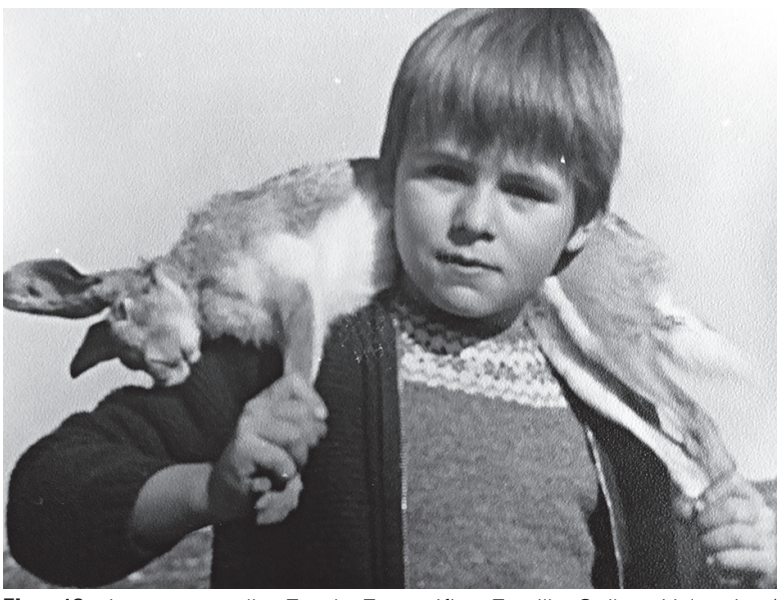

Figs. 10. Joven aprendiz. Fondo Fotográfico Familia Guibert-Valencia. / Young apprentice. Guibert-Valencia Family Photography Collection.
Es decir, según el autor el cazador posee una percepción de ese 'paisaje' que le hace interpretar el medio natural bajo un prisma 'preobjetivo' y global. Esto le mantiene alerta y atento con todos sus sentidos, de manera múltiple e interactiva con el entorno que conoce. Sin embargo, quizás esté influenciado por sus inquietudes personales, su importante relación con unos perros fieles y el deseo o "impulso de captura", lo cual hay que señalar que es su fin último.

Esa sensación de acto social pero restringido e íntimo ha estado vigente y se mantiene hasta el día de hoy en la región estudiada. Se trata de algo personal pero compartido en cuadrilla con pequeños gestos no muy ritualizados aunque sí asentados. De esta forma, Miguel Guibert señala que en Navarra no se ven ritos como 'el bautizo de sangre' que si se dan en otras regiones pero cuando un mocé logra su primera pieza, el padre es el primero que le saluda y abraza junto al perro. Así, ahora, igual que antes, es habitual que cuando una cuadrilla va de caza, una de las personas sea la encargada de preparar el almuerzo para todos los compañeros permaneciendo el día que le corresponda sin cazar. Eso sí, los cazadores de Corella, antes de partir no dudan en comer juntos al alba el sutil refrigerio llamado arranque o cáustico. Éste no se compone más que de un pequeño pedazo de pan casi seco y sin miga en el que depositan aceite junto con ajos picados, sal y piparras picantes con objeto de coger fuerzas. En cualquier caso, este sentido de micro comunidad o de grupo cohesionado no se aprecia ni en el caso ya mencionado de aquellos pastores trashumantes que cazaban por necesidad ni en el de los alimañeros o furtivos que se verán a continuación.

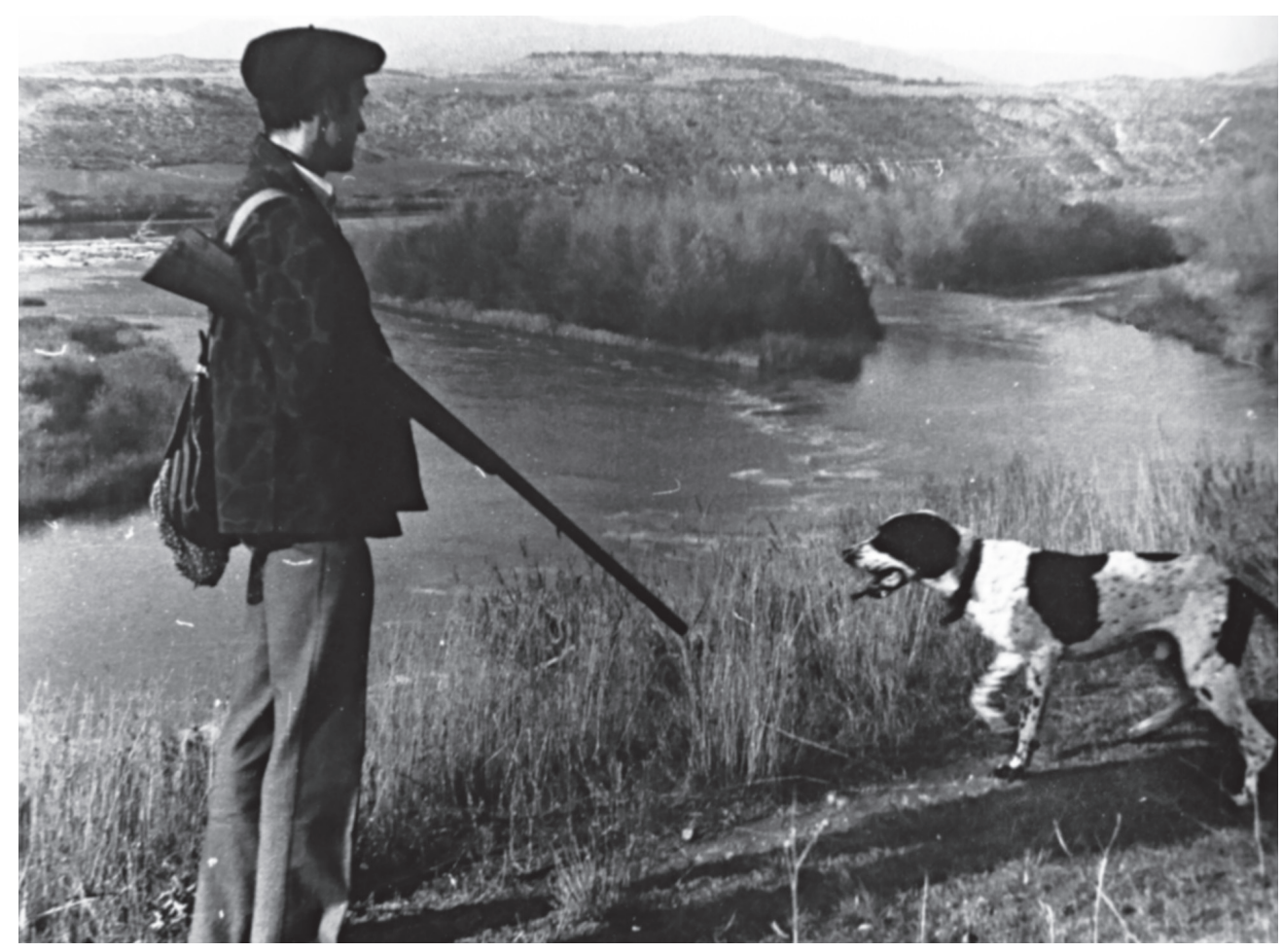

Figs. 11. Cazador y perro oteando el terreno mugante a la Bardena. Fondo Fotográfico Familia Guibert-Valencia. / Hunter and dog watching from above the terrain adjoining the Bardena. Guibert-Valencia Family Photography Collection. 


\subsection{El rapiñero}

Con tal apelativo se conoce a los alimañeros, denominados también matadores de fieras en las propias Ordenanzas de las Bardenas -Artículo 81: de la extinción de animales dañinos-. La definición de rapiñero se concreta aún más en el "articulado de la normativa que rige el disfrute del territorio". En él se especifica que "se abonará de fondos comunes el premio determinado por las Leyes o Reglamentos Administrativos a los matadores de fieras, muertas o cazadas en las Bardenas, dando razón del sitio, día y hora en que hubieran sido cogidas o muertas. Si la Comisión tuviese alguna duda el presentante deberá justificar su relación en la forma que dicha Comisión estime necesaria". Así pues, se puede indicar que el oficio de este tipo de cazador a encargo o recompensa consistía básicamente en capturar todo tipo de animal perjudicial para los moradores del comunal -ganaderos, agricultores, yeseros, etc...- (Barandiarán y Manterola, 2000: 654). El pago por sus muertes era independientemente del uso que se le iba a dar con posterioridad a la pieza -alimento, venta, o simplemente desecharla-, y sin reparar en medios ni consecuencias. Sólo se le exigía probanza de su captura ya fuera mediante la exposición del animal muerto o de una parte representativa de él como la cabeza o la cola.

Hay que señalar que si bien en el territorio bardenero han sido contratados alimañeros para poder finalizar con determinadas plagas -lobos, zorros...- en momentos concretos, también lo fueron con otros fines. En ciertas ocasiones este paisaje semiárido ha sido recorrido por rapiñeros a los que se había encomendado acabar con determinados animales no de rapiña sino peligrosos para otras piezas objeto de la caza o las personas. La presencia de estos alimañeros en la Bardena está constatada documentalmente desde por lo menos el siglo XVIII. En 1791, el valle congozante de Roncal recibía un dictamen del abogado del mismo acerca de las gratificaciones que por la caza de animales dañinos se estaban pagando en las Bardenas ${ }^{9}$. Un año después era el vecino de Arguedas Diego Falces quien demandaba al fiscal y a la villa de Arguedas. El demandante exigía recibir el pago correcto de las gratificaciones que se le debían por matar lobos. Diego afirmaba que en el territorio de las Bardenas había matado una "loba cerbaña". El arguedano aseguraba que otros rapiñeros habían matado "cada uno una loba en los mismos términos habiéndoles satisfecho inmediatamente los ocho ducados" mientras que a él no le habían pagado nada ${ }^{10}$.

Hoy en día el lobo ha desaparecido tanto del paisaje natural como del cultural en las Bardenas. Han sido largas centurias de persecución con métodos más o menos violentos pero eficaces al fin y al cabo en su propósito (Garde, 2017: 127-140). En las últimas déca- das del siglo XX se daba por casi extinto en toda la Navarra pastoril y en particular en la Bardena (Barandiarán y Manterola, 2000: 655). Sin embargo, como se señaló, su presencia sigue viva en diferentes enclaves del territorio donde la toponimia menor nos recuerda su presencia antaño. Así, se puede hablar del término de Cabezolobo, cuyo nombre nos remite a la existencia de una posible antigua lobera. En cualquier caso, las loberas fueron abandonadas como sistema de caza con la difusión de armas de fuego desde el siglo XVII (Jimeno, 1993: 91-92; Barandiarán y Manterola, 2000: 664). Aún con todo, desde 1537 hasta la actualidad, ha existido en las Bardenas el topónimo Matalafiera o Barranco de Matalafiera -1746- que nos remite a la ardua labor de acabar con estas presas dañinas (Jimeno, 1993: 82).

Por otro lado, se encuentran enclaves con nombres muy significativos al respecto: Plana de Mesalobar, Portillo de los Lobos, Puente de los Lobos o el más humilde Cabaña del Raboso -zorro (Iribarren, 1997)-. Así mismo, en la toponimia histórica todavía son más los nombres de lugar que nos remiten a diferentes alimañas: Barranco de los Rabosos en 1877, Las Raboseras en 1874 y el antiguo Val de la Mota de la Fiera de 1537 (Jimeno, 1993). A su vez, se ha de recordar que el término cubilar en lengua castellana remite al cubil o madriguera y escondrijo de fieras. Sin embargo, este vocablo en el contexto de la Ribera navarra y valles pirenaicos como el de Roncal denota el abrigo o redil semi-improvisado donde se resguarda el ganado.

De forma sencilla, junto a las barreras de los corrales, se colocaron espantapájaros con ropajes viejos o cacharros de metal para espantar a los intrusos (Barandiarán y Manterola, 2000: 660). En otros casos frente a depredadores menores como roedores o pájaros carroñeros los pastores emplearon a sus canes, llegándose a intitular a los más hábiles en estos recados de eliminación de depredadores como perros ratoneros. Sin embargo, no siempre resultaron los citados artilugios y los perros muy eficaces contra las alimañas y había que buscar métodos más expeditivos. Así, para muchos vecinos de poblaciones colindantes y congozantes que contaban con escasos recursos, el oficio de alimañero suponía asegurarse un jornal extra (Barandiarán y Manterola, 2000: 676 y ss.). Así lo determina uno de los informantes locales que sentencia cómo "los animales estaban en el campo y el campo es de todos. Eran tiempos malos y esta afición me permitió obtener más dinero con la venta de la caza que con el cuidado del ganado. Lo que empezó como una necesidad se llego a convertir en un oficio". Según ha dicho un encuestado, tanto los zorros como las águilas reales eran un peligro extremo para la caza que él y otros capturaban y de la que obtenía recursos económicos. Por lo tanto,

\footnotetext{
${ }^{9}$ Archivo Junta del Valle de Roncal, Caja.013/020.

${ }^{10}$ ARGN, TT.RR., 093833.
} 


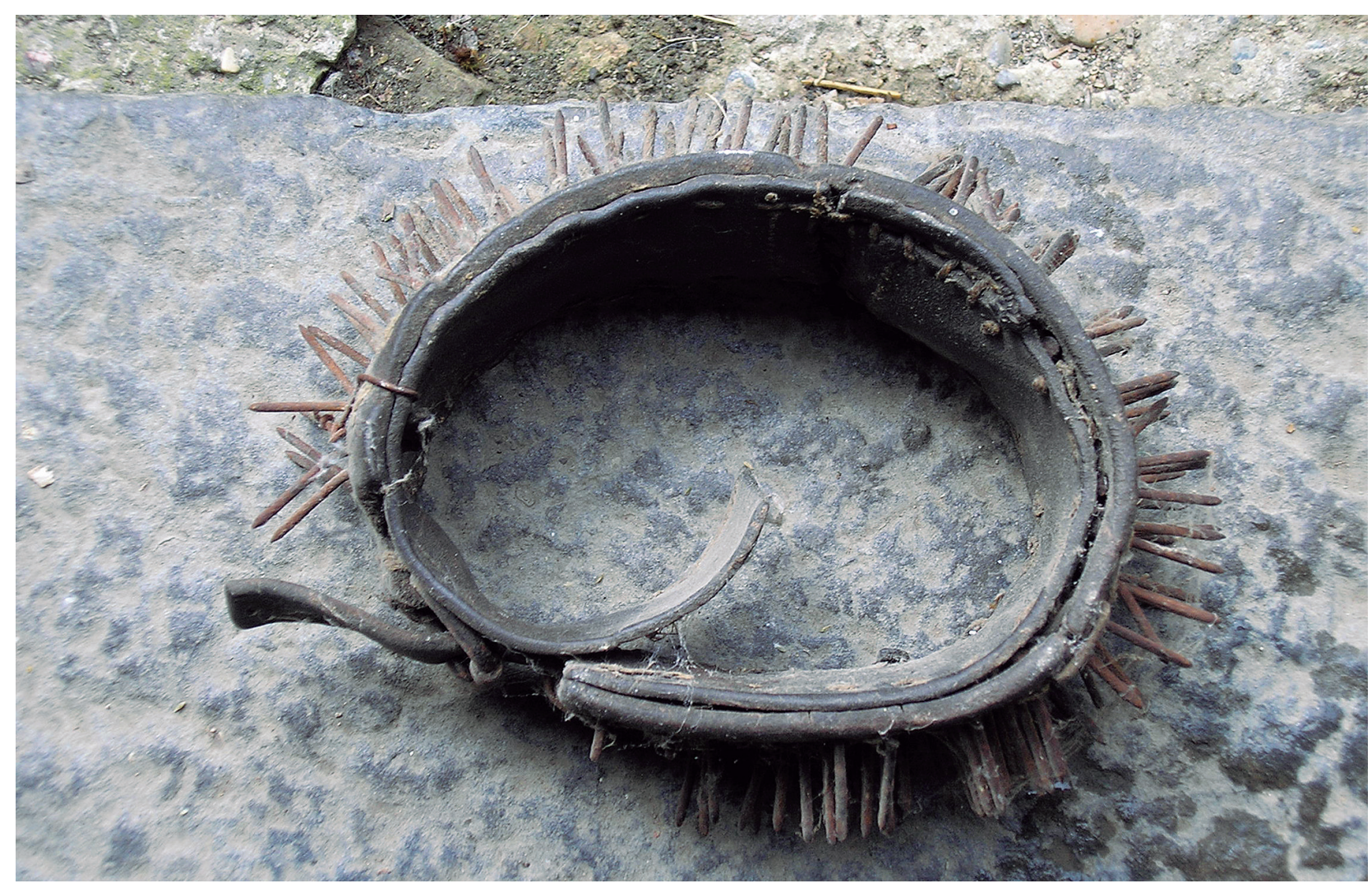

Fig. 12. Carlanca contra lobos de los perros pastores. Txaro Mateo / Iron spiked shepherd dog collar against wolves. Txaro Mateo.

la captura de estos animales -hoy protegidos- era más que necesaria y su eliminación una necesidad, así que "nido que veía, nido que destruía". Recordemos que especies como el raboso o zorro, a pesar de habérseles otorgado algunas cualidades meritorias como la astucia, han sido condenados dentro del folklore popular con estigmas peyorativos, acusativos y que han potenciado la aversión y persecución de las poblaciones locales hacia ellos (Rabal y Sánchez, 2007: 111-128; Mariño, 2014: 614-617).

Aún en algunos casos entre los informantes nos encontramos ante una mentalidad que parte de una situación social, económica y de percepción de su nicho ecológico casi de subsistencia, que a día de hoy ha desaparecido (Márquez, 2015: 61-72). Por ello, ha sido, y es, difícil la consecución de la nueva política de protección de determinadas especies que está llevando la Junta de Bardenas dentro de un territorio declarado desde 1999 Parque Natural por el Gobierno de Navarra y desde 2000 como reserva de la biosfera por la UNESCO. Es por ello que en la actualidad, los alimañeros son contratados de forma legal y más controlada por la Junta de Bardenas para poder terminar con plagas certificadas que causan problemas a cultivos o explotaciones ganaderas. Como señala el informante Miguel Guibert, la defensa ante posibles depredadores ha tenido distintas interpretaciones en el último siglo. Se observa cómo a mediados del pasado siglo XX la con- sideración de alimaña era amplia. Por el contrario, con la normativa actual el control de depredadores o sobrepoblaciones afecta principalmente a aquellos animales que están considerados como tales en las órdenes forales de Vedas o Plagas. Hay que recordar que esta regulación es aprobada anualmente por la administración foral navarra y limita mucho el tipo de capturas. Por otro lado, el resto de especies no incluidas en ella tienen distintos tipos y niveles de catalogación. Sí es verdad que entre las principales que son controladas por la caza mediante batidas o al salto está de nuevo el zorro, seguido por un elenco de especies de córvidos.

\subsection{El furtivo}

Dentro del entorno cinegético y sus principales protagonistas ha existido siempre un reducido grupo que, o bien por necesidad, o bien por disfrute de lo prohibido, se ha movido en el lado ilegal de la caza (Sánchez, 2013: 19). A través de la documentación histórica de tipo legal se ven multitud de casos de tal práctica y de su persecución o consecuencias punitivas. Ya en la Edad Moderna, Alejandro Peris (2017: 67) puntualiza que los castigos eran severos abarcando desde la pérdida de sus perros, las multas o el destierro. Así, a lo largo de la historia, como es de esperar, el furtivismo en las Bardenas también ha sido habitual, debido a las condiciones de aislamiento que presenta el lugar -inac- 
cesibilidad, gran extensión, limitación de recursos de vigilancia.... Sin embargo, la concienciación social es cada vez mayor en las comunidades aledañas. Además, el respeto por los valores de la naturaleza y su conservación se puede considerar como incorporado en gran parte al colectivo de cazadores. Es verdad que como en todo grupo humano siempre habrá excepciones en el comportamiento común, pero por norma general se respeta la legislación.

Los enfrentamientos entre los furtivos y las autoridades competentes que vigilaban la prohibición de caza en tiempos de veda o con técnicas ilegales han sido constantes. Durante toda la Edad Moderna ya encontramos multitud de pleitos en los que se demandaba a vecinos de las localidades circundantes de la Bardena por usar ese tipo de aparejos, desacato, injurias o resistencia incluso ejerciendo violencia o malos tratos a los guardas reales ${ }^{11}$. En 1662 las cosas fueron aún peores. Ese año el fiscal denunciaba a Pedro de Asín y Zabalza, alcalde de Cáseda, por no detener a los hermanos Unanua en esa localidad -no congozante de las Bardenas-. Ambos casedanos estaban acusados de agresión en las Bardenas a tres vecinos de Sangüesa, mientras cazaban conejos, y acabando con la vida de alguno de ellos. Si bien es cierto que los había que en vez de llegar a las manos prefería resolver las desavenencias con los guardas en los tribunales. En 1545, este fue el caso de Juan Guerrero, vecino de Tudela, que exigía a Gil de Borau, guarda de las Bardenas Reales, la restitución de una acémila y de varios aparejos requisados por el agente al considerarlos prohibidos en la caza, y no así por el demandante. Años después, en 1598, la villa de Mélida acusaba a varios guardas de la Bardena de agredir y dar malos tratos a vecinos del municipio al ser aprehendidos realizando ciertas labores y cazando ilegalmente en ese comunal ${ }^{12}$.

A día de hoy, la Bardena constituye en este sentido un coto de caza regulado. Su vigilancia la ejerce directamente el guarderío designado por la Junta del comunal. Paralelamente existen otros niveles diversos que constituyen el conjunto de agentes de la autoridad con potestad para intervenir en caso de detectarse posibles infracciones. Una de sus labores ha sido la de realizar encuestas en la zona que han permitido determinar cuáles son las especies afectadas y los métodos empleados para su captura de forma furtiva. Es obvio que está todo mucho más controlado, aunque hasta los años 70, la caza furtiva constituyó para muchos que la practicaban un sistema importante de obtención de recursos económicos. Este tipo de prácticas ilegales les permitía no sólo ampliar los productos alimenticios integrantes de su dieta, sino incluso ganar cierto dinero extra con la venta de pieles y carnes de algunos animales muy demandados. La 'conciencia ecológica' era com- pletamente diferente. Se trataba de sobrevivir, y como expone la reflexión de uno de los vecinos encuestados: "lo que nosotros hacíamos no era furtivismo, era hambre". Incluso los antiguos guardas a veces eran comprensivos con convecinos muy necesitados. Es más, se dio la paradoja de que, dado el conocimiento de los sistemas que tenían sobre la caza, algunos furtivos fueron contratados como vigilantes posteriormente.

Es obvio que la miseria existente durante muchos años contribuyó a incrementar el ingenio y la picaresca de estos cazadores ilegales. Algunos de ellos señalan que era habitual tener que pagar mordidas a los agentes: "para ser furtivo, tenías que saber a quién le podías regalar algo y a quien no". Además, el conjunto de la población de la región tenía conocimiento de quién practicaba el furtivismo y, en muchas ocasiones, este hecho contribuyó a que se tendieran trampas entre ellos y se echara "un falso cebo para que los guardas fueran a por alguien y mientras tanto se cazaba". Sin embargo, los furtivos eran ya personas resabiadas y tenían los modos más dispares de guardarse de cualquier detención o denuncia.

\section{TÉCNICAS DE CAZA}

A tenor de los perfiles que ya se han expuesto, se puede afirmar que la práctica de la caza en las Bardenas requiere tener unas habilidades determinadas y un conocimiento exhaustivo del medio sobre el que se lleva a cabo. Como se ha visto, este tipo de destrezas fueron trasmitidas tradicionalmente de generación en generación, de padre a hijo, por línea masculina. Antes de producirse la popularización de la ocupación cinegética como actividad amateur o deportiva, ya se daban innumerables modalidades tradicionales de caza. Es verdad que antaño las hubo también prohibidas, pero en la actualidad muchas de las que antes eran permitidas son consideradas como ilegales y han ido desapareciendo. Otras han podido persistir pero con grandes restricciones. Se podrá apreciar cómo existen unas que por su sencillez nos remiten a etapas iniciales y a los primeros cazadores del género homínido, pero que por su versatilidad y eficiencia se han mantenido hasta hace pocos años. Otras en cambio exponen la evidente evolución que se dio en el arte de la caza y de las armas empleadas para tal fin. Se enumerarán en orden alfabético según su denominación popular.

A Farol: Se trata de un sistema de caza ilegal utilizado por los furtivos que consistía en dejar aturdidos a los conejos y liebres mediante los faros de un tractor o coche. Una vez, que el animal queda ofuscado y confundido se procedía a su captura mediante la vara, escopeta o lo que se tuviera a mano para golpearlo y darle muerte.

\footnotetext{
${ }^{11}$ ARGN, TT.RR., 063887, 144929, 011591, 072988 y 102008.

${ }^{12}$ ARGN, TT.RR., 287980, 027097 y 252977.
} 


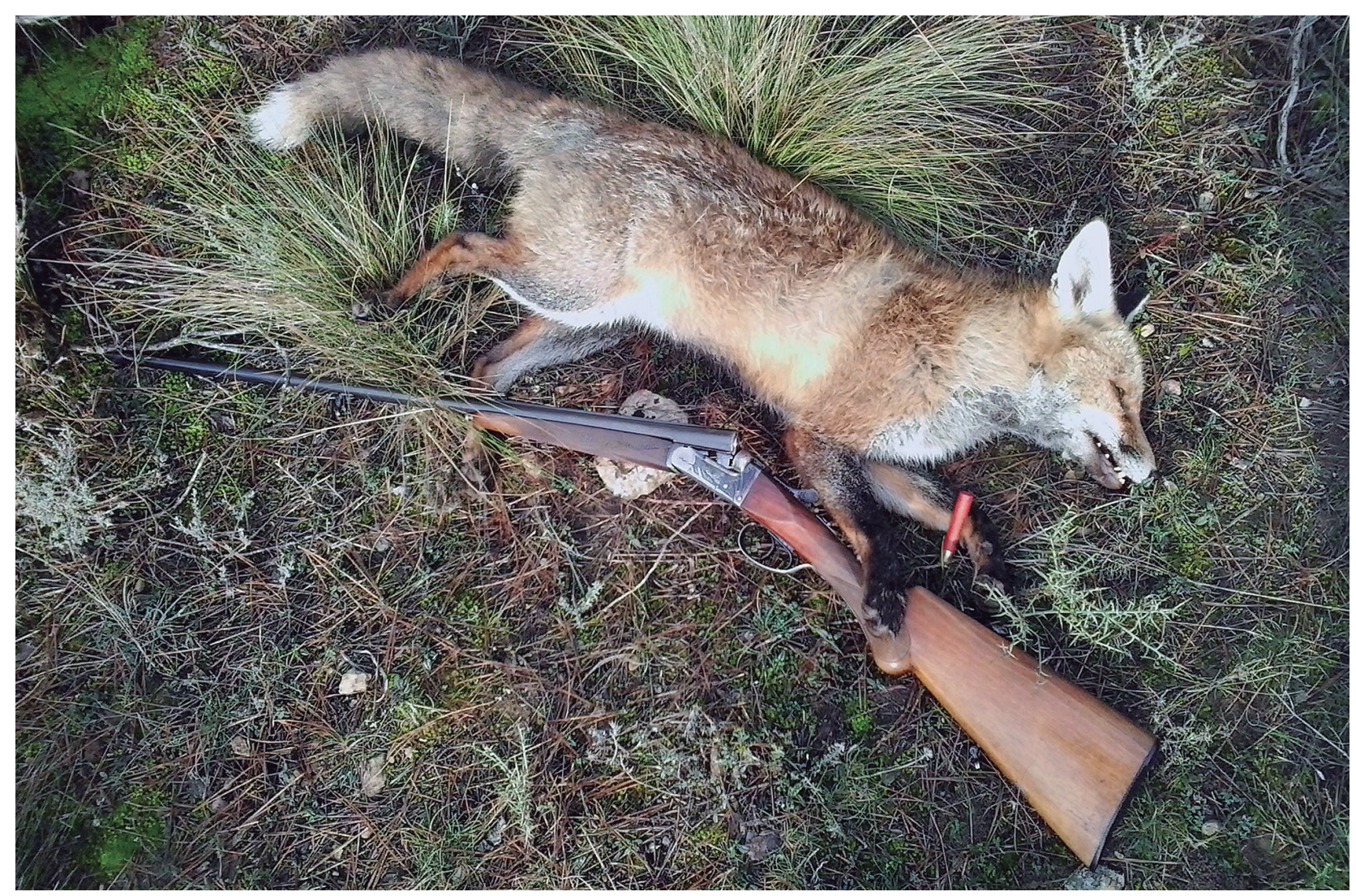

Fig. 13. Zorro cazado al salto. Fondo Fotográfico Familia Guibert-Valencia. / Fox jump shooting. Guibert-Valencia Family Photography Collection.

Al salto: Este método era denominado también al levante. La técnica era empleada esencialmente para la captura de la liebre, aunque también se ha utilizado de forma ocasional para la caza del conejo, la perdiz y el zorro. El cazador esperaba al momento en que el animal "saltara" o "se levantara" abuzado por su perro y en ese momento abatía a la pieza con la escopeta.

A la espera: Para cazar perdices, palomas u otras especies de aves se han establecido improvisados esperaderos en puntos estratégicos de paso y vuelo de estos animales. Estos consisten en pequeñas hondonadas protegidas por ramajes entrelazados, arbustos o parapetos pétreos que permitían al cazador mantenerse a cubierto y escondido de la vista de los pájaros (Nebot, 2002-2004: 1598-1599). En las Bardenas, como queda recogido en la obra coordinada por Jimeno (1993), un topónimo histórico de 1926 hace explícita referencia a uno de estos emplazamientos en el territorio: Esperadero de Perdices -1926-. Puede que la perdiz fuera una de las piezas más preciadas pero la paloma torcaz -Columba palumbus- no se le queda a la zaga en este ranking de presas destacables. La caza de esta ave exigía de gran habilidad en la Bardena, sobre todo porque, según relatan los informantes, "tiene una vista muy buena y en cuanto observa la presencia del cazador cambia la dirección". Por lo tanto, la captura debe efectuarse a la espera aguardando camuflado en un puesto de escucha y caza -aguardadero- con mucha paciencia y sigilo. En esta técnica, la costumbre es salir a cazar temprano y estar ya preparados en el esperadero al momento del amanecer. Según los informantes, es entonces "cuando pasan más bajas y también cuando comienzan a ascender para cruzar La Negra y es en ese momento cuando hay que disparar".

Batida: hay que señalar que esta modalidad de caza se reglamentó en las Bardenas en 1992. Desde esa fecha se planteó su orientación hacia la captura del jabalí, el corzo y el zorro. La presencia del corzo en las Bardenas es muy reciente -desde el año 2010-; y este animal se ha comenzado a cazar también con el método de batida o sino el de al rececho. En tal sistema el cazador debe acercarse, viento en contra y con sigilo, lo más posible al animal para abatirlo con un arma de fuego. A su vez, debe estar apoyado por un conocedor del territorio y/o un auxiliar que porte las piezas y el material de caza. Aun con todo, se trata de una técnica poco asentada dentro de los grupos de cazadores de la Bardena y se ve más propia de cazadores no vinculados a cuadrillas de la zona o de otros lugares. De igual manera, la captura del jabalí también es reciente en territorio bardenero. Hasta los últimos veinte años ésta no fue una pieza habitual de la práctica tradicional cinegética del entorno. En cualquier caso, la modalidad de batida consiste en provocar el resaque con perros y 


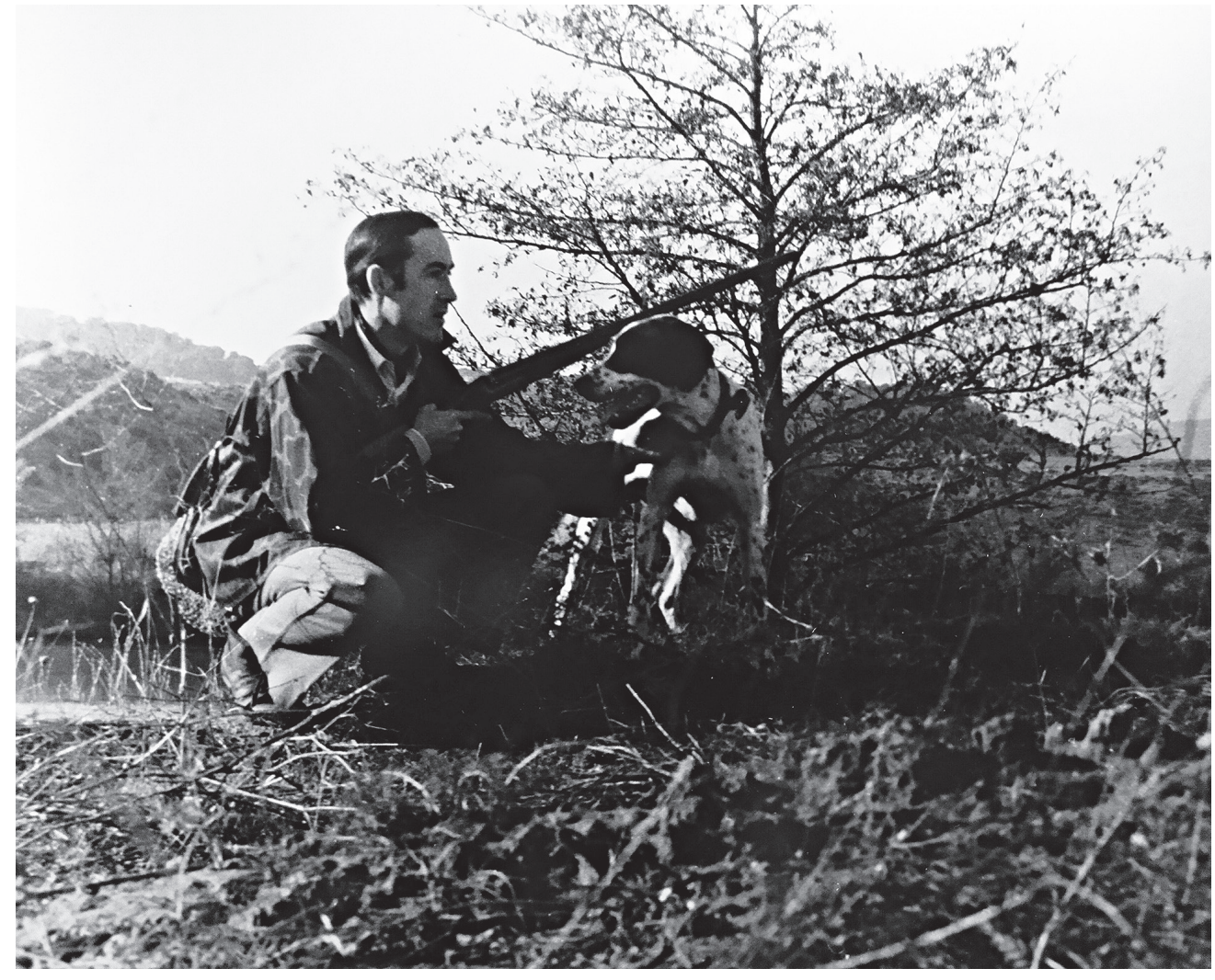

Fig. 14. Cazador y su perro a la espera. Fondo Fotográfico Familia Guibert-Valencia. / Hunter and his dog waiting. Guibert-Valencia Family Photography Collection. la huida de las presas de sus áreas de refugio. Mientras tanto, la cuadrilla de cazadores aguarda con escopetas instalada en determinados posicionamientos de espera localizados en los puntos de salida o huída que puede tener el animal. Esta costumbre de rastreo y acoso con resaqueadores se ha ido imponiendo en las últimas décadas en algunos grupos de cazadores de la Ribera aunque antiguamente era más común sólo en la montaña navarra.

Bichar: Se denomina así a la caza del conejo con hurón -Mustela putorius furo- ya que al citado animal lo llaman bicho. Utilizados en la actividad cinegética hace cientos de años, prenden de forma fácil a los lagomorfos en sus madrigueras (Mariño, 2014: 328; Sánchez, 2013: 190-191). La técnica de caza con bicho esta registrada en las Bardenas desde el siglo XVI. En 1556 el fiscal acusaba a varios vecinos de Caparroso por cazar conejos y liebres en tiempo de veda y con "aparejos prohibidos". Entre este tipo de métodos que empleaban estaba el uso del hurón acompañado de redes y arcabuces. Y era tal su grado de actividad de andar "tirándoles a la espera y al chito con tanta continuación que tienen huida la caza de los dichos términos y Bardena de mucha abundancia de ella". Además en los procesos se ve cómo se usa sobre todo furtivamente en tiempo de veda, el perro junto al hurón y con el cascabel puesto en el bicho. En 1777, el fiscal del Reino acusaba a Martín de Laurendi, alias el Cojo de Perenton, y a otros compinches por cazar con estos animales en el término y jurisdicción del monasterio de La Oliva -Carcastillo- y de las Bardenas. En concreto en la Bardena se les vio en el paraje Ilamado El Paso, sito encima de la llamada Cueva de Caparroso, y en el de Chirmendia "con hurones en contravención a repetidas leyes de este reino" a los cuales les colocaban un cascabel y esperaban con redes en el resto de bocas de las madrigueras. Un siglo antes, en 1651, a quienes se acusaba era a varios vecinos de Arguedas, por cazar no sólo conejos sino también perdices con "hurones, redes y otros aparejos prohibidos en los términos de la villa y en las Bardenas". Además "al suelo" abatían corzos y venados. Esta técnica también la empleaban en apresar perdices "tirándolas al vuelo y al suelo y es tanta continuación que han cazado y cazan que tienen huída la caza de dichos términos y Bardenas"13. Es cierto que en la Bardena el hurón además de compañero de muchos cazadores legales ha sido un amigo íntimo del furtivo -bichero- y constituyó junto a los cepos y lazos una de las herramientas más utilizadas por estos. Hay que señalar que dentro de la legalidad se ha per-

${ }^{13}$ ARGN, TT.RR. 287769, fol. 2; 134521, fol. 149; 207078, fol. 1 y 299153, fol. 1. 
mitido su empleo en determinadas ocasiones con el fin de combatir plagas. Así fue en los años 70 del siglo XX cuando la presencia del conejo supuso un peligro para los cultivos existentes en el comunal. Entre los cazadores era frecuente ponerles un nombre propio a sus hurones. De esta manera, cuando estaban dentro de la galería buscando al conejo podían atender a la llamada del dueño sin tener tiempo para dañar a la pieza. Otro modo de citarlos era dando palmas de una forma determinada como clave entre el dueño y el animal. Se les proporcionaba una alimentación basada en "sopas de leche con un huevo y queso" evitando darles sal. En ocasiones se les daba hígado para mejorar su resistencia. Para trasladarlos al campo los introducían en unas cajas de madera sujetas con correas o en alforjas que se sostenían sobre las caballerías. Una de las formas de caza consistía en introducirlos en los aguallevaos o galochos, galerías formadas cerca de los barrancos por acción del agua, desde la parte baja e incitarles para que subiesen hacia lo alto. Así, el conejo ascendía con rapidez desde sus escondites en la hondonada y salía a cielo abierto sin la posibilidad de retroceder por el acoso del hurón. Cuando el hurón se introducía por las madrigueras se necesitaba para la caza la participación de dos personas. La forma más habitual de hacerla era introducir el animal por una de las bocas o cañas de la madriguera en busca del conejo. Esto propiciaba que su inquilino huyera y en ese momento se atrapaba utilizando redes. Estas redes se fabricaban en la misma casa del cazador. Para evitar que los hurones permanecieran dentro de la madriguera comiéndose al conejo que habían capturado o se quedasen trasconejados -atrapados detrás de él después de haberle dado muerte- colocaban al animal un bozo -pequeña liza atada al hocico con una cuerda a modo de bozal-. Esta era la forma que impedía que el hurón atacase al conejo hiriéndole el cuello y matándolo. Además, con objeto de no perder al hurón durante la caza y poder oír sus movimientos en el interior de la madriguera se le colocaba al animal uno o dos cascabeles en el cuello. De este modo se sabía de forma rápida si el animal se había quedado bloqueado en el interior y se podía emprender su recuperación y la de la presa. Para tal fin se cavaba con una azada sobre la madriguera intuyendo su trazado por el sonido de los cascabeles. Por otro lado, este sonido les permitía intuir por la boca de la madriguera que iba a salir el conejo huyendo y así atraparlo. Esta información se comunicaba entre los cazadores presentes con un gesto, dando palmadas o arrojando una piedra cerca de la salida que se creía sería utilizada. Como medida de protección en esta técnica los cazadores se ponían guantes ya que los hurones muerden. En otras ocasiones les cortaban o limaban los colmillos con unas tenazas o limas evitando futuras heridas en sus manos o perder piezas engullidas por sus hurones.

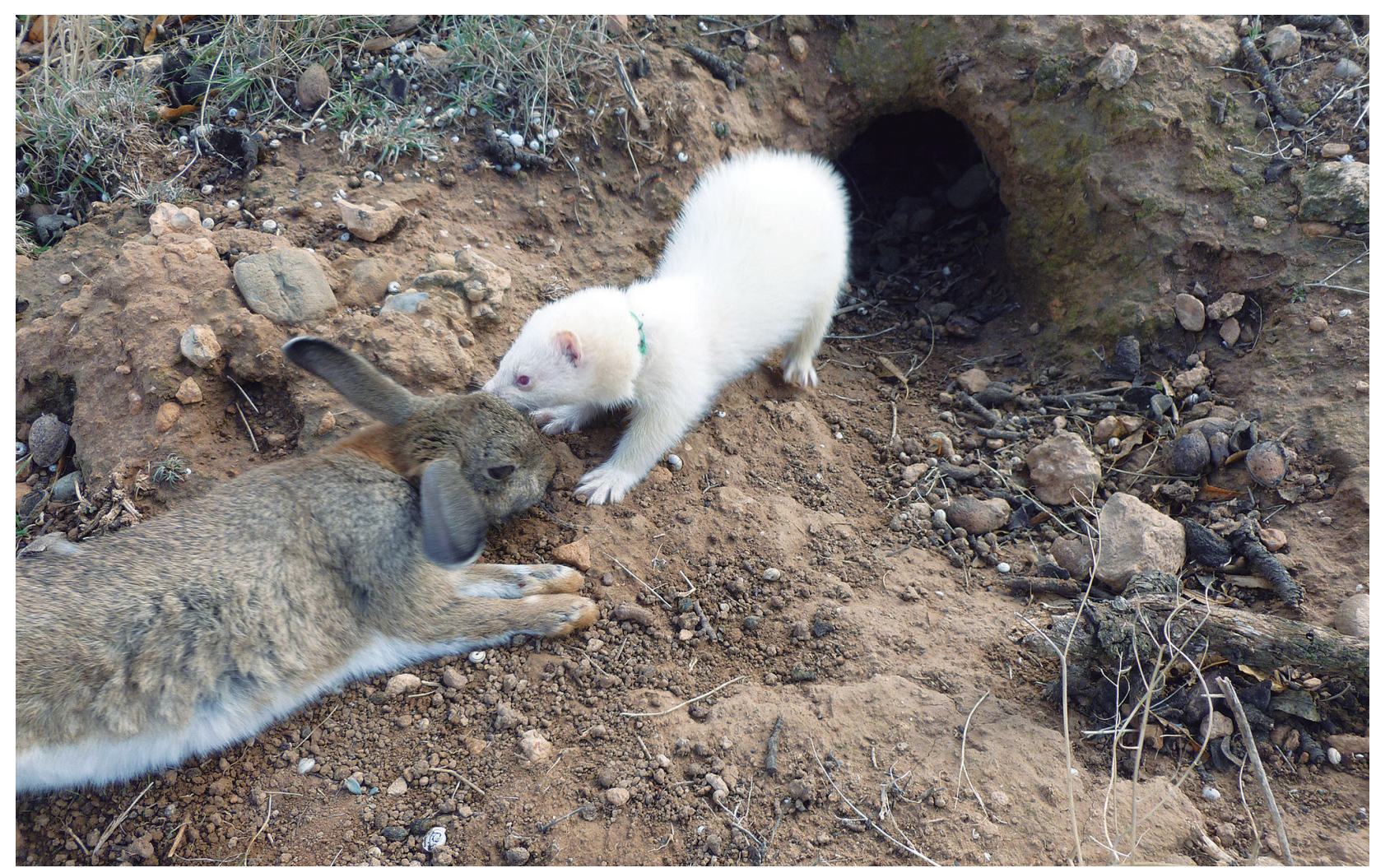

Fig. 15. Hurón saliendo de la madriguera con la presa. Fondo Fotográfico Familia Guibert-Valencia. / Ferret coming out of the burrow with the prey. Guibert-Valencia Family Photography Collection. 
Caza con perros: En determinados métodos de caza, sobre todo en la captura de liebres y conejos, era imprescindible contar con la ayuda del perro. A lo largo de la historia han sido diferentes las razas caninas empleadas en las Bardenas por los cazadores. Al margen de los perros pastores, hay que mencionar otros tipos de canes como los galgos o agalgados -similares a los primeros en porte pero no de casta purao los ratoneros. Actualmente, en Navarra, y la Ribera por ende, la raza de perro más común es el podenco u otros ejemplares resultado del cruce de estos con otras razas. También es relevante el papel que juega el perdiguero navarro -al que a veces se emparenta con el llamado pachón de Navarra- por ser resistente y habilidoso en la caza menor de pluma y pelo. Hay que señalar también que antiguamente sobresalía el conocido como braco navarro que era hábil en la caza mayor y hoy se considera extinguido (Gómez, 1999). En cualquier caso, fuera cual fuera la raza del animal, en esta técnica el fundamento del éxito pasa por saber utilizar las cualidades de los perros para la captura de las piezas. Así, el uso de perros para cazar el conejo dependía de si su captura se estaba realizando de forma legal o furtiva. Si la caza era furtiva, no era habitual que los cazadores llevarán perros ya que sus ladridos podían alertar a los guardas. Sin embargo, cuando la caza se practica legalmente, se deja que el animal chucholetee -husmee- el rastro y encuentre la pieza escondida. Entre los perros utilizados para la caza del conejo los informantes señalan a los ya mencionados galgos y los perros ratoneros "que aprendían solos" el oficio. Eso sí, todos debían poseer una serie de condiciones como "ladrar poco y coger la pieza sin romperla"; es decir, sin producirles desgarrones o heridas. Si además el can no es ruidoso y se dirige de forma lenta buscando a la presa "se consigue que la pieza no se alerte y quede resguardada entre las matas". Por otro lado, a los perros que se emplean para la captura de la liebre se denominan perros de acuse. Y cuando se iba a cazar acompañado del can y se hacían grandes caminatas se decía que se estaba cazando a la andada. En el caso de la liebre una técnica aún vigente es la caza con galgo. Se trata de una modalidad sin empleo de arma de fuego en la que los perros atraillados son soltados por el cazador en el momento del levante y el éxito de la captura depende de la velocidad y habilidad del can.

Cepos: Este es un método muy usado en las Bardenas para la captura de pájaros, conejos, liebres y zorros (Boza, 2008: 247 y ss.). El tamaño del cepo y el cebo dispuesto en él están condicionados por la presa a la que va dirigido. Así, para capturar pajaricos no eran grandes artilugios sino ingenios artesanales que se solían elaborar en casa llamándose costillas y a sus utilitarios costilleros. Para su fabricación se empleaba una "tablica", un "clavico" y unos resortes que se reaprovechaban de los alambres extraídos de las ruedas de las bicicletas inservibles. Dentro del cepo se colocaban varias alaícas -hormigas aladas- que se compraban a los aluderos. Éstas eran del gusto de los pájaros y cuando iban a comérselas quedaban atrapados. Para ello, se colocaban sobre el chicholete del cepo, y así, cuando los pájaros se apoyaban y picoteaban para desenganchar la alaíca, la trampa se cerraba. Por el contrario, para cazar conejos, liebres o zorros los cepos utilizados se denominan alcatrapa -Arguedas- y eran verdaderas trampas de metal con gran fuerza de presión sobre la víctima. En determinadas ocasiones, los cazadores llegaban a poner cepadas-grupos de cepos- de hasta 100 unidades dispersas por el terreno. Para poder transportar mejor el gran número de animales cazados solía ser habitual atarles las patas traseras -empiolarles-. Para la captura de liebre y conejo los cepos se colocaban al anochecer en los cirrieros, lugares cercanos a la madriguera con excrementos del animal, con objeto de revisarlos y retirarlos al amanecer si habían logrado su objetivo. Otro lugar y momento óptimo para su instalación era durante la cosecha en los grandes montones de paja que se acumulaban en el campo ya que es un lugar habitual donde se guarecen liebres y conejos. Así mismo, otro cazadero bueno eran aquellas zonas donde existían bardales, matas de moras silvestres, ya que son uno de los lugares preferidos de los conejos para disponer su cama o madriguera. Además, este animal tiende a repetir "viciosamente" la misma ubicación año tras año de estos escondrijos por lo que los cazadores solían tenerlos más que localizados. Cada conejo suele tener más de una cama, pero sólo en una extensión de poco más de un kilómetro. En el caso de los zorros el cazador también tiene que tener un conocimiento amplió de sus hábitos y deben ser especialmente resistentes los armazones de hierro (Satrústegui, 1978: 214). Se sabe que cuando salen de las zorreras van a buscar la comida a lugares concretos a los que ya han acudido en otras ocasiones. Como señala un encuestado son "esos sitios los que había que buscar y donde se colocaban los cepos" Ilegando hasta ellos rastreando las sendas o tallas que han dejado a su paso los rabosos. Entonces, para capturarlos se colocaban unos cepos grandes de hierro que al atrapar al animal le rompían una de las patas cuando éste se "peleaba" con la trampa para poder escapar. Este hecho redundaba en el costo de las pieles ya que si ésta quedaba muy dañada se pagaba menos por ella al cazador. Una vez apresado el zorro los cazadores se ayudaban de una manta para atraparlo sin que les atacara si seguía vivo. Los cepos destinados para el lobo eran todavía más grandes y resistentes, Ilamándose loberos. En todas estas modalidades de cepo el sistema base estaba constituido por un resorte elaborado mediante la fuerza de tensión que ejercía una rama o vara, de diferentes materiales. Una vez activado éste por el peso del animal, el sistema ejercía la liberación del seguro de la trampa lo que hacía articularse a ésta y apresar a la pieza (Boza, 2008: 277). 


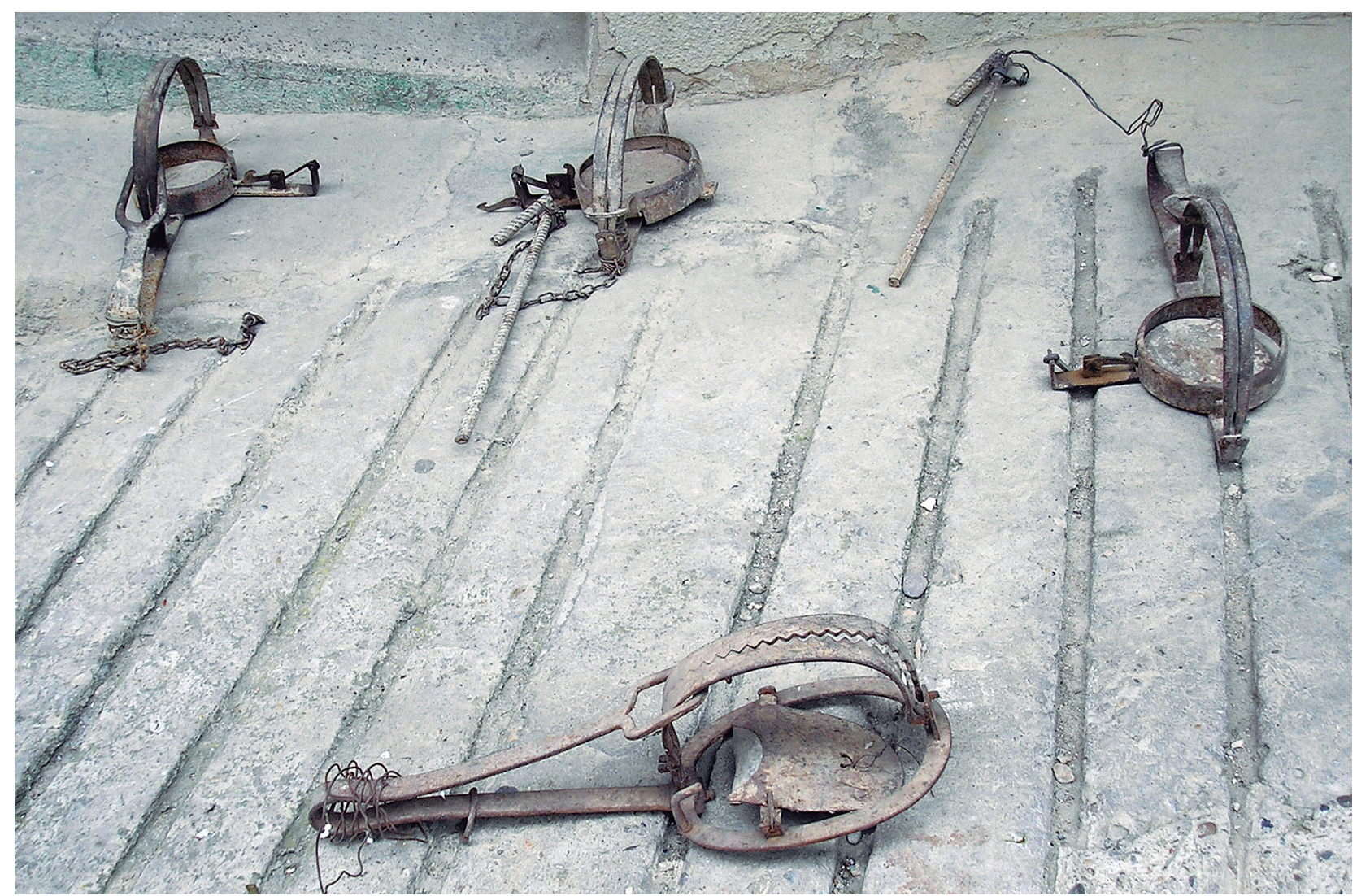

Fig. 16. Cepada completa en las Bardenas. Txaro Mateo. / Complete set of stocks in the Bardenas. Txaro Mateo.

Cimbel: Para la captura de la paloma torcaz se ha llegado a emplear el cimbel que no es sino un señuelo o añagaza elaborada con siluetas de plástico imitando a ese animal y su comportamiento para atraer a las torcaces salvajes y hacerlas bajar confiadas, entrando en el campo de tiro de la escopeta del cazador. El cimbel puede constituirse también con un balancín donde se coloca una paloma viva como señuelo.

Jaula trampa: Se trata de una estructura mecánica que presenta en su interior un dispositivo que se acciona cuando la presa se encuentra dentro y le impide la posterior salida. La caja o arquilla podía ser o bien simétrica o más estrecha en un extremo (Satrústegui, 1978: 206-214; Boza, 2008: 291). Para que el animal se acercara a la jaula se utilizaba un cebo casero. En muchos lugares, éste solía consistir en comida o preparados cuyas recetas se mantenían en secreto (Satrústegui, 1975 y 1978: 216). Hay que señalar que este método de cajas o jaulas trampa se ha empleado para la captura del zorro de forma legal, previa autorización del Departamento de Medio Ambiente del Gobierno Foral.

Lazos: Junto con los cepos y los hurones se trata de uno de los sistemas de caza más repetidos para la captura de conejos, liebres, zorros y perdices en las Bardenas. El ingenio consiste en colocar lazos en aquellas zonas donde es habitual que las posibles pie- zas estén a resguardo, ocultas entre los matorrales o senderos marcados por las pisadas de los animales. En general, estaban elaborados con sirga y una ferralla a modo de palo. Para que este sistema diera resultados había que tener en cuenta una serie de premisas como conocer el peso del ejemplar deseado o sus características anatómicas ya que de ello dependía el tipo de lazo, sus dimensiones y la altura para colocarlo. Cuando este método se utilizaba para cazar el zorro la piel del animal cazado valía más en el mercado ya que no resultaba tan dañada. En Santacara se usaba un lazo provisto de nudo corredizo hecho con crin de caballo trenzado ya que se creía que el zorro tenía dentera de morderla para liberarse de la trampa (Satrústegui, 1978: 205-206). El dispositivo se colocaba en las entradas de las madrigueras (Barandiarán y Manterola, 2000: 669). Cuando el lazo se utilizaba para la captura de perdices también se fabricaba con pelos de la cola de un caballo.

Lica o liga: Este ungüento de zumo del muérdago pegajoso se usaba para la captura de pájaros pequeños - pajaricos- acompañada de otros elementos o artimañas. Así, en ocasiones se disponía junto a la gardincha-cardenchas secas- colocando encima unas plumas. También, era habitual untar un palo o vareta con esta masa para propiciar que las aves se quedaran 


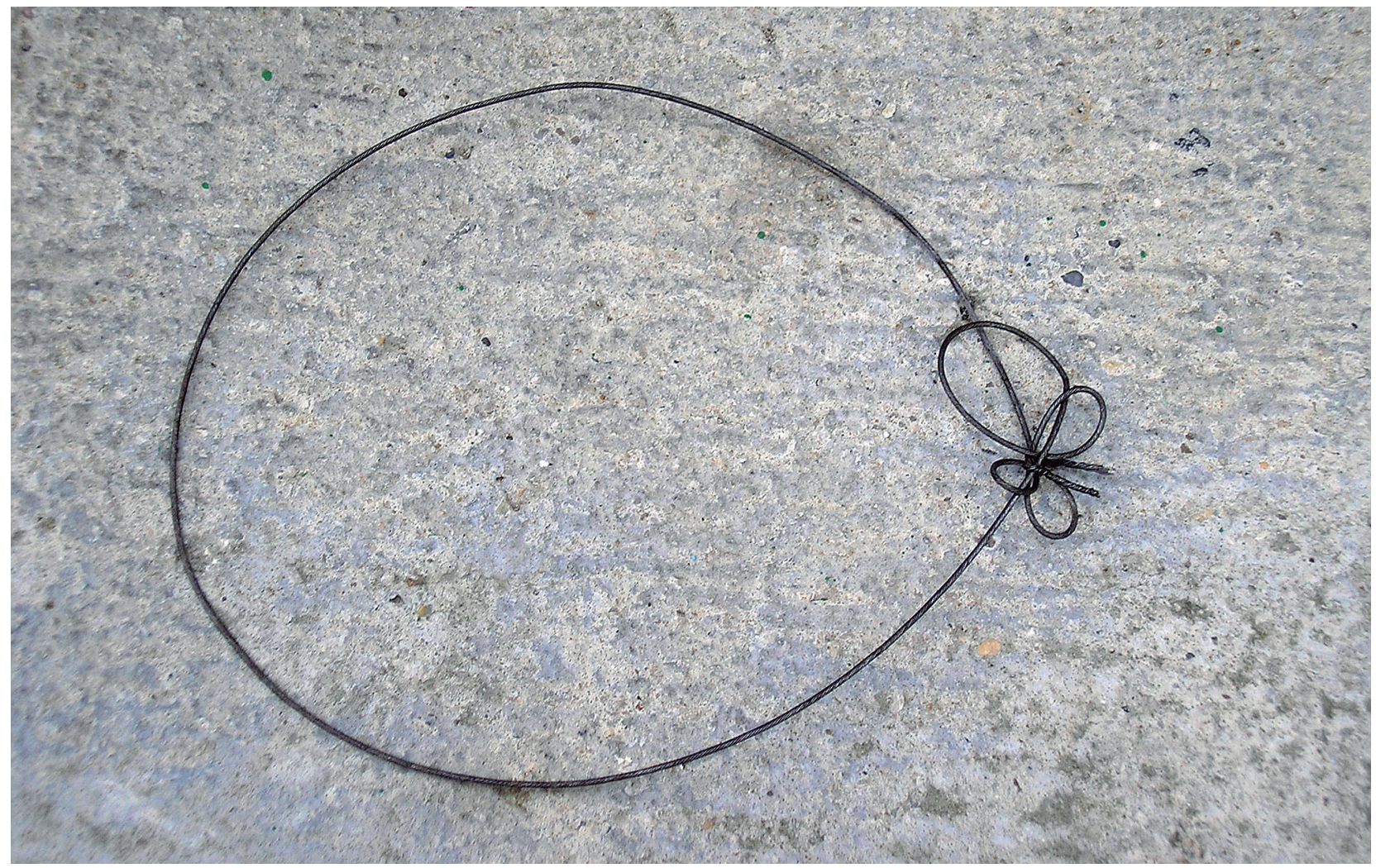

Fig. 17. Lazo metálico corredizo. Txaro Mateo. / Metallic slipknot. Txaro Mateo.

pegadas al posarse en él. Además, para lograr que el pájaro se acercara se imitaba su canto. Estas pequeñas aves capturadas solían pertenecer a la familia de los fringílidos, destacando las cardelinas -Carduelis carduelis-. A estos pájaros los cazadores también las atraían emitiendo chafarrillas que no eran sino silbos imitando el canto de la hembra.

Losa: Se trataba de una roca plana que se colocaba casi en vertical sobre el suelo y es sostenida por un palo para depositar en la oquedad resultante el cebo u otro 'palo trampa' horizontal. Cuando el animal se arrimaba al lugar la varita de madera era movida produciéndose la caída de la losa encima de la presa y la muerte de ésta.

Pajahumo: Esta modalidad consiste en prender fuego a un manojo de esparto o espartera e introducir el humo por una de las entradas de la madriguera o cado del conejo. Mientras, se apostaban redes en el resto de las entradas para capturar al animal cuando intentara huir. Esta tipología de técnica cinegética se podía desarrollar también empelando al hurón para capturar más fácil la presa.

Red: Es una técnica que se utilizaba para la captura de tordos principalmente, por ello a los que empleaban este método se les denominaba torderos o reteros. Esta práctica se llevaba a cabo en invierno ya que los cazadores controlaban por donde pasaban las bandadas de tordos y procedían a colocar grandes redes en las que los pájaros quedaban atrapados. Al verlos llegar, y posicionados de forma estratégica, daban palmadas asustando a los tordos haciendo que se dirigiesen a la señalada trampa. Los encuestados comentan que "para los de Novillas, aunque no fueran congozantes era un método habitual y se les solía ver con él por las Bardenas".

Vara: Con este nombre la población de la zona se refiere al cayado utilizado por los pastores para el control del rebaño y como herramienta donde apoyarse durante el descanso. Dicho bastón también ha sido el método empleado por ellos para matar conejos y liebres e incluso farnacas -crías de estos lagomorfos y lepóridos-. El sistema era sencillo ya que simplemente consistía en arrojar el palo contra el animal y si éste no se moría por el golpe se le remataba. En este sentido, indican los informantes que cuando un rebaño entraba a pastar a una finca y había una liebre, está se quedaba parada y el rebaño se "abría" a ambos lados del animal. Este hecho era visualizado por el pastor que procedía con la vara a cazarla y matarla. Otro de los lugares donde este sistema tenía gran eficacia era en las fincas donde había fascales o hatillos de gavillas de cereal. Estos eran utilizados como refugio por los conejos, así que el pastor se acercaba a los mismos y hacía ruido para que los animales huyeran y golpearles al salir a descubierto. 


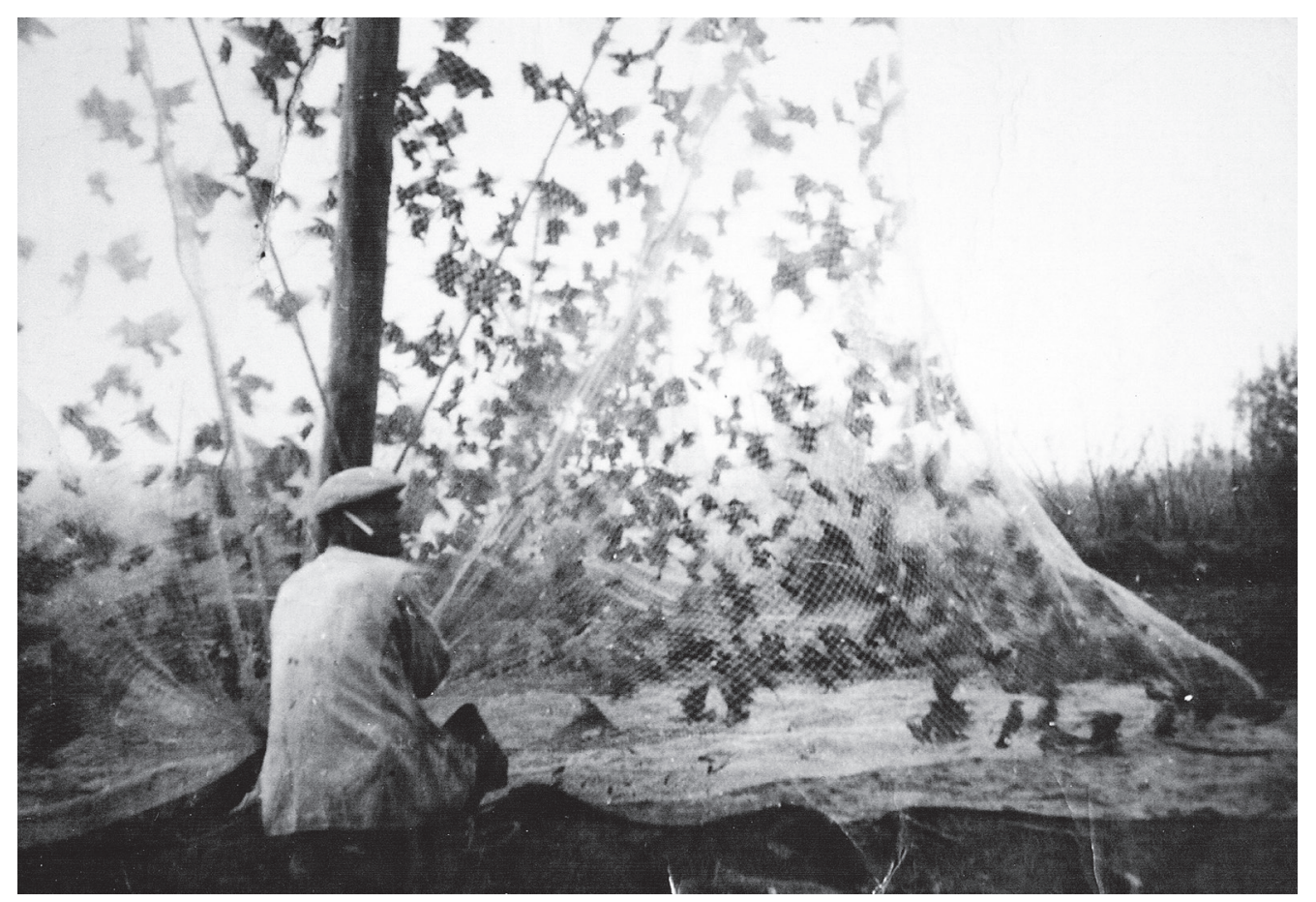

Fig. 18. Retero capturando una bandada de pájaros. Ayuntamiento de Arguedas. / Retero capturing a flock of birds. Council of Arguedas.

Como se puede ver, la captura tradicional ha consistido fundamentalmente en diferentes métodos de trampeo. Sólo desde la irrupción y generalización de las armas de fuego, su caza se ha llevado ya a cabo mediante sistemas que permitían atrapar al animal a distancia. Hasta los años 70-80 del siglo XX, son numerosos los encuestados que han comentado la escasez de armas de fuego en manos de los cazadores bardeneros ya que "sólo los ricos tenían escopeta". Además, apuntan que cuando se empleaban solían ser de un cañón únicamente y los cartuchos se elaboraban en sus casas ya que "si la pieza no caía a la primera, la captura salía cara". En estos casos el perro se ha convertido en un aliado mucho más importante para poder rastrearlos y abuzarlos -azuzarlos- para abatirlos. Los acaudalados también usaban como munición destinaba a los lobos y a algún otro mamífero unas bolitas gruesas de plomo denominadas perdigones loberos.

\section{EL DESTINO DE LAS PRESAS}

Se puede apreciar cómo históricamente, en las Bardenas la especie cinegética principal cazada para consumo doméstico ha sido el conejo silvestre. Esto se debía en gran medida a su abundancia en el territorio. Sin embargo, hay que señalar que con la irrupción en los años setenta del siglo XX de enfermedades como la mixomatosis y posteriormente la neumonía hemorrágico-vírica, las poblaciones silvestres sufrieron un drástico descenso del que todavía no han remontado. Otras especies cinegéticas principales han sido la liebre ibérica y la perdiz roja. Esta última considerada como "la reina de la caza menor" debido a la bravura que mues- tra en los lances con los cazadores (Compaired et al., 2003: 87; Mariño, 2014: 373). De carácter secundario, en las Bardenas encontramos especies cinegéticas de caza menor como el ánade real -Anas platyrhynchos-, asociado a balsas o pequeños humedales, la paloma torcaz, el zorzal -Turdus sp.- o la becada -Scolopax rusticola- en zonas arboladas de la Negra. El destino de estas aves era dispar. Así mientras que los gorriones - Passer domesticus- se capturaban para comer, las cardelinas se destinaban a la venta.

En cuanto a la caza mayor, al margen de alimañas, una especie con presencia e interés cinegético ha sido el corzo. Así mismo, como ya se señaló, en los últimos veinte años una especie en claro aumento dentro del mundo cinegético ha sido el jabalí. Aunque se trataba de un animal de poco interés para los cazadores en tiempos anteriores, ahora, debido a la creación de nuevos regadíos en el perímetro de Bardenas, ha encontrado cobijo en barrancos y el matorral mediterráneo aumentando en número y en atractivo para la caza. Muchas de las especies mencionadas están consideradas también presas de caza en el territorio mugante de la Bardena de Aragón (Compaired et al., 2003: 82, 87 y 189).

Hasta la mitad del siglo XX, los pobladores de las Bardenas mantuvieron una forma de vida en cierto modo autárquica. Tanto aquellos que pastoreaban de invernada en el interior de este gran comunal como los que acudían desde sus pueblos congozantes de forma esporádica con el fin de ejercer diferentes labores o trabajos vieron en los recursos cinegéticos un complemento a su alimentación y economía doméstica. La carne de las presas constituía un gran aporte de 


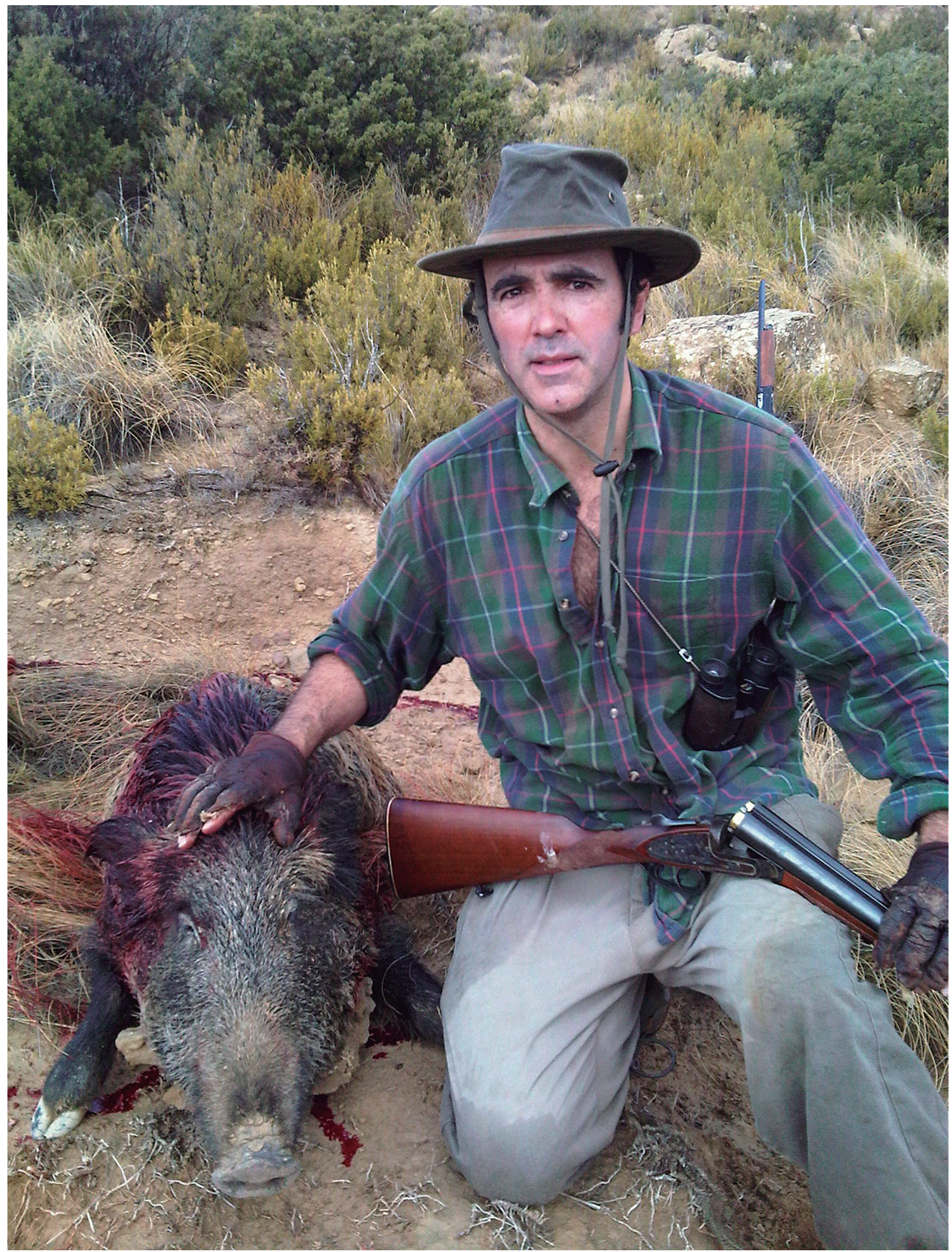

Fig. 19. El jabalí, una especie de caza al alza en las Bardenas. Fondo Fotográfico Familia Guibert-Valencia. / The boar, a kind of hunting upwards in the Bardenas. Guibert-Valencia Family Photography Collection. 
proteínas, grasas y minerales que hubiera sido difícil adquirir en esa cantidad a través de los mercados o ferias locales. El hambre azuzaba en algunos periodos -guerras y momentos de malas cosechas- a estos vecinos; los cuales veían cualquier humilde captura -pajaricos- como verdaderos manjares que "se comían de un solo bocao". A la par, el poder cazar suponía una vía importante de acopio de alimentos para el grupo conformado por los pastores trashumantes Con la captura de pequeñas piezas -conejo, liebre, aves y pajaricospodían incrementar la escueta variedad de alimentos que consumían y que fundamentalmente se componía de conservas, salazones, embutidos y algunos de sus corderos. Sin embargo, otra parte del fruto de la caza se utilizó como un medio de ampliación de ingresos y capitales en las economías personales. Así, algunas de las piezas más importantes se destinaban a la venta o el trueque a cambio de otros productos primarios o manufacturados. En muchas localidades de la Ribera era habitual el intercambio de las presas obtenidas por productos básicos como pan, leche -litro de leche por conejo--, aceite, harina, etc.

Así mismo, para los alimañeros constituía el ingreso esencial de su oficio y un modus vivendi particular. Desaparecido el lobo, en el contexto de estos personajes el zorro adquirió un papel protagonista y relevante. Del raboso se utilizaba todo empezando por la piel o las colas. Aún en los años 80 del siglo pasado, el precio de una de estas pieles bien curtidas podía llegar al valor de 3.000 pesetas. Además, su valía se incrementaba o disminuía a tenor del estado en que se encontrara en el momento de la venta. Por ello, además de desollar bien al animal, era importante que durante la captura no sufriera alteraciones o heridas significativas que estropearan la belleza de su cuero y pelaje.

Es cierto que a nivel de cultura gastronómica o culinaria popular determinadas presas tenían un éxito o aceptación mayor. Esto no sólo repercutía en su buen precio sino, como ya se mencionó, en la existencia de verdaderos cazadores furtivos que veían en ellos una interesante fuente de ingresos. Entre las más destacadas está el conejo, que no sólo se vendía sino que era plato habitual en las mesas de las familias de estos cazadores clandestinos. Por supuesto, otro destino de estos animales era la venta en el mercado legal o el intercambio de su carne, pieles o colas por otros productos. Dependiendo de la cantidad de piezas capturadas, estas eran vendidas a los vecinos de los pueblos o a zonas más alejadas En algunas ocasiones llegaron incluso a ser transportados en autobús hasta Pamplona. La piel de estos pequeños mamíferos se espelletaba y se secaba para venderlas a los peleteros. En cualquier caso, otro miembro de la familia de los leporidae, la liebre, era la reina en cuanto al pecio de sus capturas. Su caza era más apreciada que la del conejo por la calidad y gusto de su carne. Esta razón hacía que fuera mayor el porcentaje puesto a la venta frente al destinado al consumo doméstico. Como señala uno de los in- formantes "la liebre la compraba gente caprichosa que tenía dinero para darse gusto, era apreciada".

Como se puede observar, el destino de los animales cazados respondía a una economía rural y preindustrial en la que tanto lo legal como lo furtivo, o las necesidades básicas como el negocio se daban la mano a diario. Se trataba de un trabajo de subsistencia como señala un dicho bardenero "cazador y pescador, mal trabajador". A día de hoy en cambio la comercialización de especies cinegéticas está regulada por un Real Decreto 118/1989, de 15 de septiembre. Además, en Navarra, la Orden Foral de Vedas de 2017 se llega prohibir expresamente la comercialización de una especie como la becada -Scolopax rusticola-. Es decir, el paradigma del hecho de cazar ha cambiado tanto legal como antropológicamente hablando. Ya no se trata de un elemento más propio de una vida tradicional sujeta al territorio sino de un rito lúdico y social con connotaciones etnológicas totalmente diferentes.

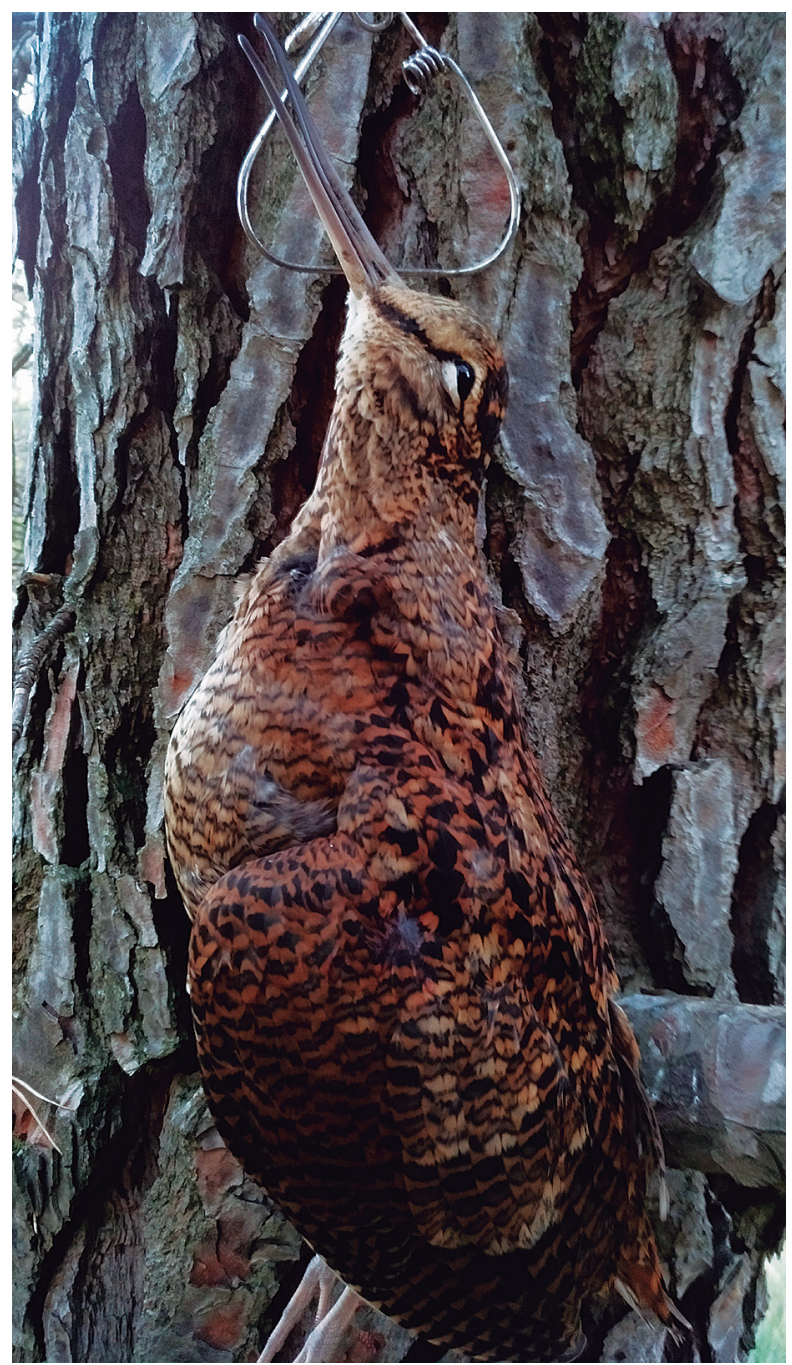

Fig. 20. Becada cobrada en las Bardenas. Fondo Fotográfico Familia Guibert-Valencia. / Eurasian woodcock bagged in the Bardenas. Guibert-Valencia Family Photography Collection. 


\section{CONSIDERACIONES FINALES}

La figura de la caza ha experimentado cierto repunte en las últimas décadas a lo largo de toda la geografía de Navarra, tanto en la Montaña como en la Zona Media o la Ribera. Sin embargo, en todos esos lugares y en las Bardenas la presencia del oficio de 'cazador tradicional' ha desaparecido. Es verdad que quienes vivían de las piezas cobradas en los lances del campo constituían un grupo minoritario en la comarca. Sin embargo, como se ha visto, también es cierto que tuvo sus pequeños momentos de auge en periodos de escasez -malas cosechas o hambrunas- o por la necesidad de acabar con ciertas plagas de animales. Así, en la época de posguerra, el hambre atenazó en esa comarca a mucha gente humilde, que optó por tener su pequeño abastecimiento de la despensa y los caudales con la caza en ese entorno semidesértico. Para algunos de ellos en ocasiones fue su único alimento, por lo que no dudaron en emplear técnicas ilegales, lanzarse al furtivismo o cazar en jornadas de época de veda. En cualquier caso, este desarrollo ocasional de la acción cinegética fue efímero y se redujo drásticamente cuando la economía mejoró y se desarrolló la mecanización del campo o se produjo el éxodo rural hacia la capital en los años 60 del siglo XX.

Aún con todo, en la Bardena, el valor social de la práctica de la caza en cuadrilla permanece visible desde hace varias centurias, como demuestra la documentación de archivo. Tal huella ha quedado también señalada en el paisaje mediante diferentes topónimos que nos hablan no sólo de métodos de captura sino de la presencia de 'fieras' o alimañas hoy ya desaparecidas, como el lobo, y en su día perseguidas.

Algunas de las técnicas de caza fueron abandonándose o prohibiéndose, pero han aparecido nuevos métodos e incluso especies susceptibles de ser cobradas. De forma conjunta fue perdiéndose parte de un conocimiento tradicional vinculado a un oficio antiguo y a una forma de interactuar con el medio equilibrada. A finales del siglo XX, la aprobación por parte de Bardenas de su propio POC supuso un gran cambio en la realidad cinegética del territorio con grandes avances en su adecuación al marco legal foral. Sin embargo, entonces el cazador se había convertido ya en una nueva personalidad recreativa alejada del modelo tradicional. Ya no se trata de un pequeño cazador que comercializa sus presas cobradas sino de la comercialización de un sector (Sánchez, 2007). Sin embargo, es verdad, por lo menos en Navarra y la Bardena, que sigue teniendo un componente colectivo donde se interiorizan en el grupo unos valores compartidos que permiten trasmitir y reproducir algunas de las pautas y comportamientos del cazador tradicional (Sánchez, 2013: 37). En definitiva, en las Bardenas, la figura del cazador ha sido un elemento más de aquellos que han dado lugar a la conformación de un desarrollo antropológico imbricado en un medio particularmente duro. Esta interrelación entre espacio y hombre ha permitido la construcción de un paisaje cultural donde se visualiza el conocimiento tradicional y un equilibrio histórico en la explotación humana del espacio Esto ha facilitado que esta comarca se configure tanto como una reserva de la biosfera como un constructo social y etnográfico independiente y vivo.

\section{FUENTES DE FINANCIACIÓN E INFORMACIÓN}

La información que se expone en el presente artículo es fruto de un proyecto ejecutado mediante un convenio de colaboración firmado entre el Ministerio de Medio Ambiente y Medio Rural y Marino y la Comunidad de Bardenas Reales de Navarra que fue encargado a la empresa Olcairum. Así mismo, los datos han sido completados con las encuestaciones de Pablo Orduna dentro del estudio para el Atlas Etnográfico de Vasconia de los grupos Etniker. En total se ha entrevistado a nueve informantes vinculados con las Bardenas, la caza u otras actividades desarrolladas en ese territorio. Su franja de edad oscilaba entre los 40 y 90 años.

\section{REFERENCIAS BIBLIOGRÁFICAS}

1871. Reseña histórica de los títulos que tienen los pueblos congozantes de las Bardenas Reales. Para su perpetuo aprovechamiento y disfrute. Zaragoza. Disponible en: http://www. memoriadigitalvasca.es/handle/10357/5735.

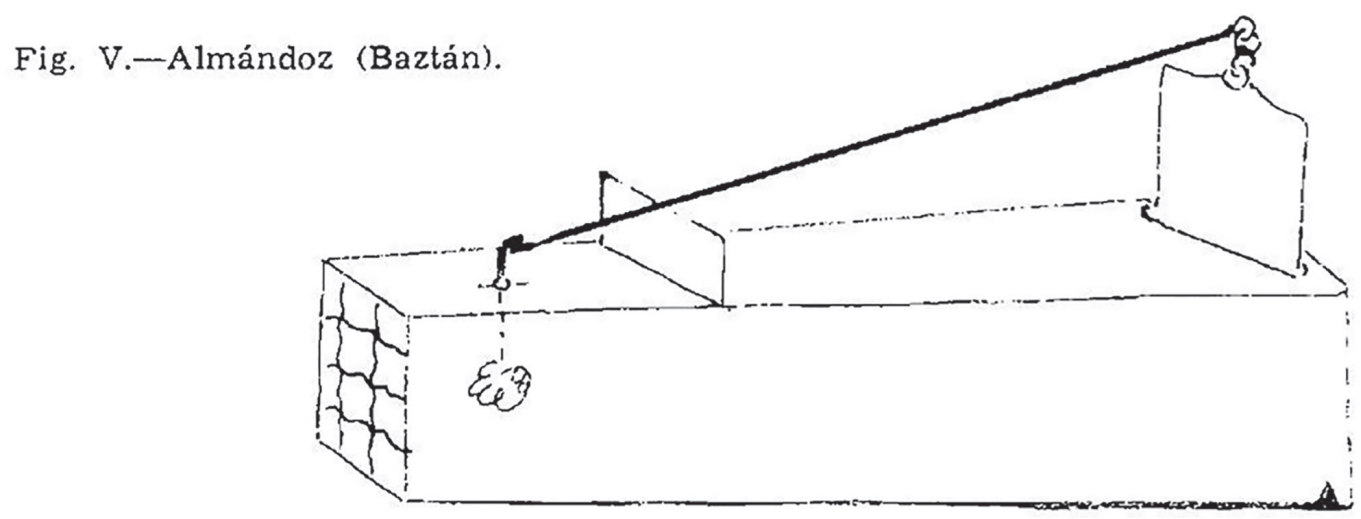

Fig. 21. Arquilla o cajón trampa para zorros (Satrústegui, 1978: 213). / Animal snare (Satrústegui, 1978: 213) 
Barandiarán, J. M., Manterola, A. (Dirs.), 2000. Ganadería y pastoreo en Vasconia. Atlas etnográfico de Vasconia. Instituto Labayru, Bilbao.

Beguiristáin, $M^{a}$ A. et al., 2010. La Cuesta de la Iglesia (Bardenas Reales): el final de la Edad del Bronce en el Ebro Medio. Cuadernos de Arqueología de la Universidad de Navarra 18, 199-225.

Boza, M., 2008. El trampeo y demás artes de caza tradicionales en la Península Ibérica. Hispano Europea, Barcelona.

Compaired, F. et al., 2003. La Bardena de Aragón. Recorrido natural por el sendero de La Negra. I.E.S. Reyes Católicos Prames, Ejea de los Caballeros.

Desir, G., Marín, C., 2009. Caracterización de la erosión en áreas acarcavadas de la FM. Tudela (Bardenas Reales, Navarra). Cuadernos de investigación geográfica 35, 195-213.

Desir, G., Marín, C., 2010. Procesos de erosión en una zona de clima semiárido de la depresión del Ebro (Bardenas reales, NE de España). Rev. C. \& G. 3-4, 63-72.

Farfán, M.Á. et al., 2004. Caracterización del aprovechamiento cinegético de los mamíferos en Andalucía. Galemys 16, 41-59.

Florido del Corral, D., Palenzuela, P., 2017. Valores culturales, discursos y conflictos en torno a la caza. El caso de las monterías sociales en Andalucía. Revista Andaluza de Antropología 13, 53-84.

Fradejas, J., 1988. Los Paramientos de la caza. Príncipe de Viana 185, 741-774.

Garde, J., 2017. Persecución y exterminio de los lobos en las Bardenas Reales y su comarca. Revista del Centro de Estudios Merindad de Tudela 25, 125-142.

Gómez, M., 1999. Diferentes razas y agrupaciones raciales caninas vascas. Naturzale 14, 181-184.

Guibert, M., 2007. La caza en Navarra: análisis y perspectivas de futuro. Navarra forestal: revista de la Asociación Forestal de Navarra 17, 22-25

Iriarte, $M^{a}$ J., 1993. El entorno vegetal en la Bardenas Reales (Navarra) durante la Prehistoria reciente. Vasconia: Cuadernos de historia - geografía. 20, 358-368

Iriarte, $\mathrm{M}^{\mathrm{a}}$ J., 2001. Un caso paradigmático de antropuzación del medio vegetal: El poblado de la Edad del Bronce de Puy Águila (Bardenas Reales, Navarra). Trabajos de Arqueología de Navarra 15, 123-136.

Iribarren, J.Mª 1997. Vocabulario navarro. Diario de Navarra, Pamplona.

Jimeno, J.Mª (Dir.), 1993. Toponimia y cartografía de Navarra. 15, Bardenas Reales. Gobierno de Navarra, Pamplona.

Lavilla, L., 2012. Marco histórico de las Bardenas Reales. Revista digital Claseshistoria 11, http://www.claseshistoria.com/ index.html.

Lozano-Valencia, P., 2017. Valoración Biogeográfica de los Paisajes Vegetales de las Bardenas Reales de Navarra a través de la Metodología LANBIOEVA. Revista de Estudios Andaluces 34, 201-225.

Mariño, X., 2014. Diccionario del simbolismo animal. Encuentro, D. L., Madrid.

Márquez, C., 2015. El control de depredadores en España: análisis histórico, incidencia actual del uso de cebos envenenados y perspectivas de futuro. Tesis doctoral. Publicaciones y Divulgación Científica. Universidad de Málaga, Málaga.
Nebot, N., 2002-2004. Vocabulario de la caza y la pesca en el habla castellano-aragonesa del Alto Mijares y del Alto Palancia (Castellón). Archivo de filología aragonesa 59-60, 1587-1608.

Orduna, P., 2013. Cronograma Histórico del derecho de pasturaje roncalés en las Bardenas Reales de Navarra". Euskonews 678 http://www.euskonews.com/0678zbk/gaia67801es.html.

Orduna, P., 2014. Aproximación etnohistórica al trabajo de la pez en las Bardenas Reales (Navarra). Revista de Dialectología y Tradiciones Populares 69, 413-433.

Peris, A., 2017. El furtivismo en los cotos reales. Revista de folklore 428, 66-70.

Rabal, G., Sánchez, A., 2007. El zorro (Vulpes vulpes) en el folklore y el habla popular del campo de Cartagena. Revista de folklore 322, 111-128.

Sánchez, R., 2007. Percepción y rentabilidad cinegética: la hipótesis del "verdadero ecologista". Periferia: revista de investigación y formación en antropología 7, 1-21.

Sánchez, R., 2013. Caza, cazadores y medio ambiente: breve etnografía cinegética. ECU, Alicante.

Santamaría, R., 2003-2016. La normativa ambiental dictada por la Comunidad Foral de Navarra. IeZ: Ingurugiroa eta zuzenbidea 1-14 (diferentes años).

Satrústegui, J., 1975. El cebo para la caza del zorro en un documento vasco del siglo XVIII. Fontes linguae vasconum: Studia et documenta 20, 237-246.

Satrústegui, J., 1978. La caza del zorro en el País Vasco. Cuadernos de Etnología y Etnografía de Navarra 29, 201-224

Sesma, J., García, Mª L., 1994. La ocupación desde el Bronce Antiguo a la Edad Media en las Bardenas Reales de Navarra. Cuadernos de Arqueología de la Universidad de Navarra 2, 89-218.

Vilaça, R. et al., 2004. Nem sempre o que parece, é: um caso de etnoarqueologia na Serra Gorda (Águas belas, Sabugal, Guarda). Norba. Revista de historia 17, 137-156. 
